\title{
Mechanical performance of highly permeable laser melted Ti6Al4V bone scaffolds
}

\author{
Arun Arjunan ${ }^{1^{*}}$, Marios Demetriou ${ }^{1}$, Ahmad Baroutaji $^{1}$, Chang Wang $^{2}$ \\ ${ }^{1}$ School of Engineering, University of Wolverhampton, Telford TF2 9NT, United Kingdom \\ ${ }^{2}$ Department of Engineering and Design, University of Sussex, Brighton BN1 9RH, United Kingdom
}

\begin{abstract}
Critically engineered stiffness and strength of a scaffold are crucial for managing maladapted stress concentration and reducing stress shielding. At the same time, suitable porosity and permeability are key to facilitate biological activities associated with bone growth and nutrient delivery. A systematic balance of all these parameters are required for the development of an effective bone scaffold. Traditionally, the approach has been to study each of these parameters in isolation without considering their interdependence to achieve specific properties at a certain porosity. The purpose of this study is to undertake a holistic investigation considering the stiffness, strength, permeability, and stress concentration of six scaffold architectures featuring a $68.46-90.98 \%$ porosity. With an initial target of a tibial host segment, the permeability was characterised using Computational Fluid Dynamics (CFD) in conjunction with Darcy's law. Following this, Ashby's criterion, experimental tests, and Finite Element Method (FEM) were employed to study the mechanical behaviour and their interdependencies under uniaxial compression. The FE model was validated and further extended to study the influence of stress concentration on both the stiffness and strength of the scaffolds. The results showed that the pore shape can influence permeability, stiffness, strength, and the stress concentration factor of Ti6Al4V bone scaffolds. Furthermore, the numerical results demonstrate the effect to which structural performance of highly porous scaffolds deviate, as a result of the Selective Laser Melting (SLM) process. In addition, the study demonstrates that stiffness and strength of bone scaffold at a targeted porosity is linked to the pore shape and the associated stress concentration allowing to exploit the design freedom associated with SLM.
\end{abstract}

Keywords: Additive Manufacturing, Titanium Bone Scaffold, Permeability, Stiffness, Strength, porosity.

\footnotetext{
${ }^{*}$ Corresponding author. Address: School of Engineering, Faculty of Science and Engineering, University of Wolverhampton, Telford Campus, Shifnal Road, Priorslee, Telford, TF2 9NT, UK. Tel.: +44 (0)1902 323829; fax: +44 (0)1902 323843.

E-mail address: a.arjunan@wlv.ac.uk (Arun Arjunan).
} 


\section{Introduction}

Under favourable conditions, bone tissue has the ability to heal itself. However, to do this the tissue has to undergo dynamic remodelling, maturation, differentiation, and controlled resorption [1]. As observed by Mouriño and Boccaccini [2], all of the processes related to the self-healing abilities of the bone involve osteoclasts and osteoblasts as the agents responsible. Nevertheless, the self-healing abilities of the bone are limited by the size of the bone defects. When it comes to critical length defects, the self-healing abilities of the bone requires to be supported either through autografts or allografts [3]. In order to complement these techniques, new biomaterials and scaffolding techniques are gaining momentum within the wider context of Bone Tissue Engineering (BTE) [4-8].

The emergence and commercialisation of Additive Manufacturing (AM) have allowed significant design freedom when it comes to tissue engineering scaffolds [9]. Within AM, Powder Bed Fusion (PBF) techniques such as Selective Laser Melting (SLM) have been shown to be effective to develop highly complex orthopaedic scaffolds [10]. Using these techniques material particles ranging from 10-150 $\mathrm{m}$ are used for printing structures allowing the possibility of highresolution porous solids $[11,12]$. Considering, this advantage, SLM is suited for the fabrication of highly complex porous designs $[13,14]$. Accordingly, this study focuses on the development of porous structures using SLM, attempting to mimic the permeability and mechanical properties of a damaged tibia using Ti6Al4V cellular structures $[15,16]$.

In previous work, anatomically shaped scaffolds with different cellular and structural properties were proposed. Even though the mechanical performance of the scaffolds was in the acceptable limit, investigation on the design proposed by Vance et al. $[17,18]$ showed higher potential for infection due to the poor permeability of the scaffold [19]. Similar results were also observed for the designs proposed by Bari and Arjunan [16] despite a porous architecture. Therefore, it has been understood that permeability of the scaffolds needs to be considered at the design stage in conjunction with stiffness and strength to complement both the mechanical and biological healing abilities of the host bone.

Accordingly, this work investigates the influence of volumetrically different porous structures on the permeability $(\mathrm{K})$, stiffness $(\mathrm{E})$, compressive strength $\left(\sigma_{y}\right)$, and stress concentration $\left(K_{t}\right)$ in comparison to the host bone being replaced. The lattice designs are carefully conceived to allow for all the qualifying attributes and to achieve the appropriate pore architecture which can enhance the artificial vascular system [20,21]. In most cases, the permeability [22,23] of a scaffold is studied in isolation without quantifying its influence on E, $\sigma_{y}$ and $K_{t}$ due to the complex pore size. A porosity and pore size of $70-90 \%$ and $450-700 \mu \mathrm{m}$ respectively are usually suggested as appropriate to approach the properties of human bone $[12,24-26]$. Considering this aspect, efforts have been placed to identify unit cell (UC) designs across a range of permeability closer to but 
above the bone being replaced. Furthermore, this work highlights the relation between the permeability and its associated parameter on complex pore geometry. The fundamental reason for considering the permeability criterion at a conception level is due to its influence on the vascular system. This approach has been supported by the in vivo studies conducted by Zhang et al. [27] among others [28,29] as beneficial for enhancing the biocompatibility of the scaffolds. According to Albrektsson [30], numerous growth factors and morphogenic proteins responsible for both mitogenic and angiogenic actions are key for bone reconstruction post-surgery. As a result, a comparable but higher than bone permeability that promotes better migration and mineralisation enhances osteointegration $[27,31,32]$.

When it came to the choice of a base material, biomedical grade Ti6Al4V was considered due to its superior biocompatibility, corrosion resistance, and low inflammatory potential [33]. The use of high strength metallic scaffolds are known to generate stress shielding at the bone-scaffold interface dictated by the difference in modulus of the host bone to the scaffold [34-38]. The stiffness of Ti6Al4V is significantly higher (110-115 GPa) than that of the cortical bone (7-30 GPa) [39-41] further validating the risk of stress shielding. In order to reduce stress shielding, the scaffold has to feature a relatively close effective elastic modulus (E) in comparison to the host bone. An approach that has been widely considered [42-44] to reduce the stiffness of Titanium (Ti) scaffolds is the use of lattice structures. Attempts to use X-Ray computed tomography (CT) data to mimic the trabecular structure of the bone have also been employed by Gómez et al. [45] and Ghouse et al. [46] with varying degree of success. On the other hand, using porosity as a parameter to control scaffold stiffness has also been experimented by Greiner et al. [47].

SLM is capable of producing scaffolds with densities as high as 99.7\% [48]. Nevertheless, Mercelis et al. [49] found that parameters such as the laser scanning and heating condition can affect the stress concentration on a part. Furthermore, SLM has a significant influence on the formation of $\alpha$ and $\beta$ phases that coexist in Ti6Al4V. The $\alpha+\beta$ phases can exist only after slow solidification, as a result of the diffusion process. Consequently, fast cooling can cause a nonequilibrium reaction, which results in the formation of martensite phase [50-52]. SLM is also known to deliver a surface finish favorable for scaffolds due to its stair-step effect. According to Li et al. [53], SLM can enhance the surface roughness and microstructure, improving the biological performance of scaffolds in vivo. A porous structure in combination with high surface roughness offers improved osseointegration by exposing more surface area for bone to scaffold contact [54]. Nevertheless, Todea et al. [55] reports that there is still room for improvement in the biocompatibility of Ti scaffolds and demonstrated the potential of further heat and chemical treatment as contributory factors.

In order to study the permeability and internal stresses that are being developed in the scaffold, appropriately validated Finite Element Method (FEM) is consulted within this study. FEM has 
been widely used as a suitable tool in many studies to predict the mechanical behavior of biomedical scaffolds. Entezari et al. [56] employed FEM to characterise the strain-energy associated with scaffolds under case-specific loading. Karuppudaiyan [57], on the other hand, used it to identify stress concentration and deformation for critical length scaffolds. Other notable works include Gallegos-Nieto et al. [58] and Montazerian et al. [59], where FEM was able to identify valuable data regarding the behavior of the scaffolds. As opposed to relative density based calculations [60], FEM allows taking into consideration the pore geometry and strut cross-section and the loading condition to predict a much more accurate behavior.

When it comes to evaluating permeability $(\mathrm{K})$; the use of overall porosity to estimate flow behavior without considering the pore geometry often results in poor accuracy. Consequently, a Computational Fluid Dynamic (CFD) analysis was employed in this study for the investigation of scaffold permeability. While a high porosity is suitable for maximizing $K$, this significantly affects the mechanical properties of the scaffold. This aspect is often not considered in studies as fluid and structural analysis are often reported in independent studies. Ali and Sen [61] reported that a combination of structural and flow analysis are necessary to identify the most suitable permeability while retaining the required mechanical strength in porous scaffold designs; a selected approach that is demonstrated in this study at porosities of 68.46-90.69 (vol. \%). As the exact requirements of the cellular geometry dependent on the properties of the host bone, there is no outright measures of success. Consequently, the study conceived six different fully porous scaffolds analysed and validated using theoretical, computational and experimental techniques. Performance of the SLM Ti6Al4V scaffolds were determined by extracting parameters for both elastic and plastic regions following uniaxial compression. The primary target was to minimise stress shielding and maladapted stress concentration while meeting all the requirement for bone ingrowth. It is proposed that permeability matched fully porous Ti6Al4V SLM scaffolds may improve the load transfer and improve bone ingrowth for potential application in large bone defects.

\section{Materials and Methods}

\subsection{Scaffold design}

Cellular architectures as proposed by Lakes [62] can be considered composites where one phase is solid and the empty space filled with fluid. The solid phase consists of a network of struts often referred to as lattices or cells. Cellular solids are typically characterised by UCs with certain symmetry elements [63]. According to Ashby [64], modelling UCs at milli or micrometer-scale allows the overall solid to be considered both as structures and as materials. As a result, the macroscopic properties of cellular solids, such as the stiffness (elastic modulus E), strength (compressive yield strength), and permeability (K) are governed by both material and structural properties [65-68]. Considering these aspects, six different UCs are conceived in this study as shown in Fig. 1 that allow for interconnected pores when assembled. 
Open cellular architecture can accommodate many different designs with varying porosity, pore size, strut thickness, shape and orientation of UCs to mimic the macroscopic properties of bone structure [69]. While Ma et al. [23] and Li et al. [70] studied commercial scaffold designs featuring standard UCs, architectural parameters for optimum mass transport were reported at a pore size and porosity of 450-700 $\mathrm{mm}$ and 70-90\%, respectively. Similar ranges were also proposed by Wong [71], Ponader et al. [72] and Chen et al. [73] as having the potential to deliver desired mechanical properties. Considering these criteria coupled with an attempt to deliver a multipore but comparable design, all UCs shown in Fig. 1 were designed with a minimum strut length of $300 \mu \mathrm{m}$ at a bulk volume of $21.95 \mathrm{~mm}^{3}$ and a relative density of $\sim 0.08-0.29$. In order to reduce geometrical discrepancy during SLM, the UCs were designed without overhangs greater than $45^{\circ}$. AM parts with overhangs above $45^{\circ}$ require support structures that are challenging to be removed without altering geometry considering the submillimeter lattices [74].
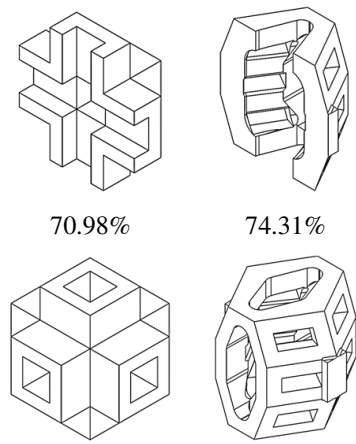

UC1

UC2

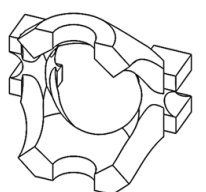

$81.23 \%$

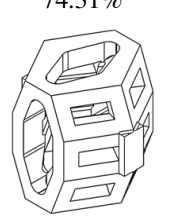

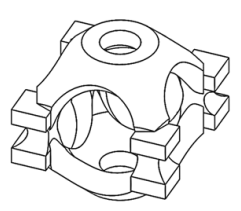

UC3

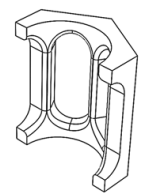

$83.01 \%$

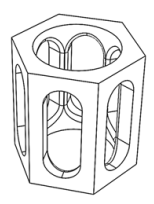

UC4
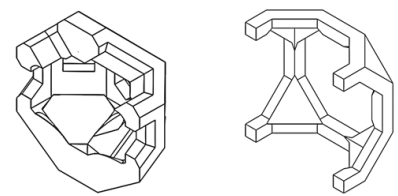

$83.10 \%$

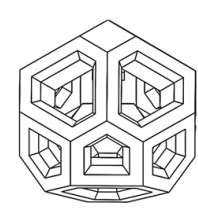

UC5

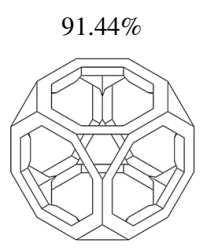

UC6

Fig. 1. Unit cell considered as the foundation for scaffold designs showing respective porosity and cross-section. Design cues for UC1, UC5 and UC6 were inspired from Egan et al. [75].

The design approach of UCs combines small and large pores, which according to Kang and Chang [76] improve vascularization subsequently enhancing bone growth. Chen et al. [77] also demonstrated that complex pores can enhance the macro-topography, where implant surfaces potentially act as a matrix hosting morphogenic proteins resulting in improved tissue regeneration. The UCs also feature enhanced boundary contacts allowing good connectivity when assembled linearly in $x, y$ and $z$ direction resulting in a stable scaffold; an approach that is considered effective for stress transfer [78].

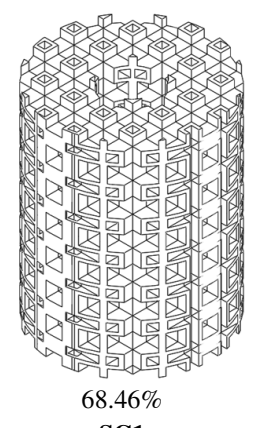

SC1

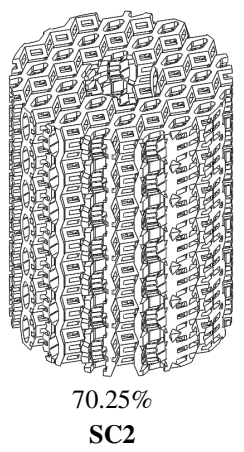

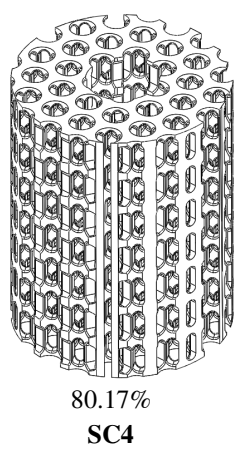

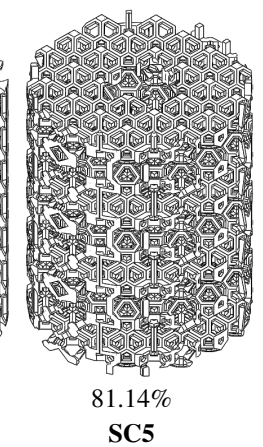

Fig. 2. Resulting scaffold designs and associated porosity after the respective unit cells were linearly arranged. 
The linear mirroring of UCs in $x, y$ and $z$ direction resulted in six respective scaffold designs as shown in Fig. 2 with properties as listed in Table 1. The global cylindrical dimensions where derived to fit an equivalent tibial segmental horizontal cross section of $180.024 \mathrm{~mm}^{2}$. The diameter of an equivalent circle that can fit the tibial cross section dictated the scaffolds outer and inner radius of $7.25 \mathrm{~mm}$ and $1.57 \mathrm{~mm}$ (rounded) at a surface area of $101.48 \mathrm{~mm}^{2}$. Accordingly, the cylindrical scaffolds can substitute an adult tibial section of length $19.6 \mathrm{~mm}$. In many clinical studies [79-81], a critical size of bone segmental defects falls between 1-3 cm resulting in more than $50 \%$ of equivalent circumferential length, where the bone cannot heal unsupported. Accordingly, the length of all the scaffolds developed in this study has $19.6 \mathrm{~mm}$, qualifying as critical length scaffolds.

Table 1. Properties of the scaffold designs generated.

\begin{tabular}{ccccccc}
\hline \multirow{2}{*}{ Properties } & \multicolumn{7}{c}{ Scaffold Design } \\
& SC1 & SC2 & SC3 & SC4 & SC5 & SC6 \\
\hline Mass $\left(m_{s c}\right) \mathrm{g}$ & 4.3919 & 4.1439 & 3.6145 & 2.7620 & 2.6263 & 1.2964 \\
Volume $\left(v_{s c}\right) \mathrm{mm}^{3}$ & 991.40 & 935.41 & 815.92 & 623.48 & 592.84 & 292.65 \\
Relative density $\left(\rho_{r}\right)$ & 0.3154 & 0.2975 & 0.2595 & 0.1983 & 0.1886 & 0.0931 \\
\hline
\end{tabular}

\subsection{Numerical analysis}

\subsubsection{Flow simulation and permeability}

According to Zhao et al. [82] permeability depends primarily on porosity, pore size and shape as opposed to the overall architecture. This means, for scaffolds composed of repeating identical units, the flow behavior of pore size and shape of the UC prescribes the permeability of the scaffold [83]. The flow simulation was performed by solving the Navier-Stokes equation for incompressible flow shown in Eqn. (1), using Ansys Fluent CFD solver:

$$
\rho \frac{\partial \vec{u}}{\partial t}-\mu \nabla^{2} \vec{u}+\rho(\vec{u} \bullet \nabla) \vec{u}+\nabla p=F, \quad \nabla \bullet \vec{u}=0,
$$

where $\rho, \vec{u}$ and $\mu$ are the fluid density $\left(\mathrm{kg} / \mathrm{m}^{3}\right)$, flow velocity $(\mathrm{m} / \mathrm{s})$ and dynamic viscosity $(\mathrm{kg} / \mathrm{m} \mathrm{s})$ in the respective direction. $\nabla$ is the vector differential operator, $p$ is the pressure $(\mathrm{Pa})$ and $F$ represents the force experienced which is zero for the case under consideration $[84,85]$. The fluid domain was modelled as a $6 \times 6 \times 6 \mathrm{~mm}$ cuboid as shown in Fig. 3 . The internal flow channels representative of the respective UCs were created using the Boolean operator, subtracting the UC solid volume from the cuboidal fluid domain resulting in the Volume of Interest (VoI) for which Eqn. (1) was solved.

The VoI has been chosen to simulate both internal and external flow through the pores. Since only a single unit cell is simulated, a larger $\mathrm{VoI}$ will be non-representative of the scaffold porosity. Furthermore, the validation study showed the current VoI represents an adequate ratio (internal/external) for the six UC arrangements considered in this study. Furthermore, a larger 
than required fluid domain will increase solution time, which is widely considered inefficient numerical modelling [86-89].

Even though the properties of water have been successfully used to simulate the K by Ali and Sen [90], this study adopts the properties of Dulbecco's Modified Eagle Medium (DMEM). DMEM is primarily used as a substitute for in vitro studies investigating bone ingrowth [91]. Based on the literature [83] at a body temperature of $310 \mathrm{~K}$, DMEM features a $\mu$ and $\rho$ of $1.45 \times 10^{-3}$ Pas and $1000 \mathrm{~kg} / \mathrm{m}^{3}$ respectively.

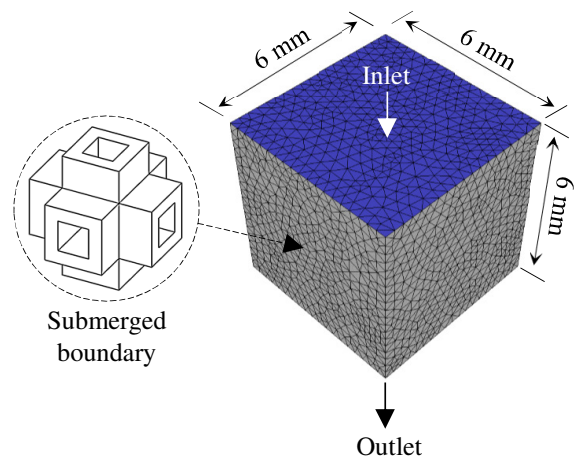

Fig. 3. Fluid domain and associated boundary conditions considered for flow simulation using CFD.

The CFD simulation was carried out at an inlet velocity of $1 \mathrm{~mm} / \mathrm{s}$ under a non-slip boundary at all contacts. The outlet was assigned a zero-gauge pressure. The model was meshed using tetrahedral elements at a maximum and minimum element size of 0.03 and $0.003 \mathrm{~mm}$ respectively, resulting in a total number of 519567 elements and 93133 nodes. Element stacking in the direction normal to the boundary using a feature called Inflation was considered to effectively capture the flow regime at the contact boundaries. This was done by inflating the mesh several layers (3) from the boundary surface. On convergence, the pressure drop across the respective UC was plotted and Eqn. (2) was used to evaluate the corresponding permeability following Darcy's law:

$$
K=v * \mu *\left(\frac{l}{\Delta p_{i-o}}\right)
$$

where $K$ is the permeability, $l$ is the length, $\Delta p_{i-o}$ is the difference in pressure between the inlet and outlet, $v$ is the inlet velocity and $\mu$ is the viscosity.

\subsubsection{Structural simulation}

The non-linear elastic-plastic performance of all the six scaffold designs were studied using FEM. The Ansys non-linear mechanical solver was used to simulate the structural behavior closely following the physical test conditions. Two cylindrical plates were modelled with a radius and thickness of $12 \mathrm{~mm}$ and $1 \mathrm{~mm}$ respectively that acted as rigid body displacement-controlled actuators as shown in Fig. 4. The thickness of the cylindrical plates is irrelevant as they were 
assumed to be rigid bodies. Consequently, the $1 \mathrm{~mm}$ thickness was randomly assumed in comparison with the overall dimensions of the scaffold being simulated. A fixed support was placed for the bottom surface and a $-10 \%$ vertical displacement ramped at 100 substeps along the $y$ direction. To avoid any spurious effects the displacement of the compression plate was constrained in $x$ and $z$ similar to the physical rig. For computational efficiency, the contact between the right body and scaffold were modeled frictionless.

The scaffolds were modelled using solid tetrahedral elemental matrix featuring a Bilinear Isotropic Strain Hardening (BISO) material model. Accordingly, the material behavior is described by a bilinear stress-strain curve where the initial slope described using E. The curve is assumed to be perfectly plastic post $\sigma_{y}$. This allows studying both the resulting stiffness (effective elastic modulus) of the structure along with the compressive strength (yield strength) in addition to the stress concentration effects, which are the parameters of interest in this study.

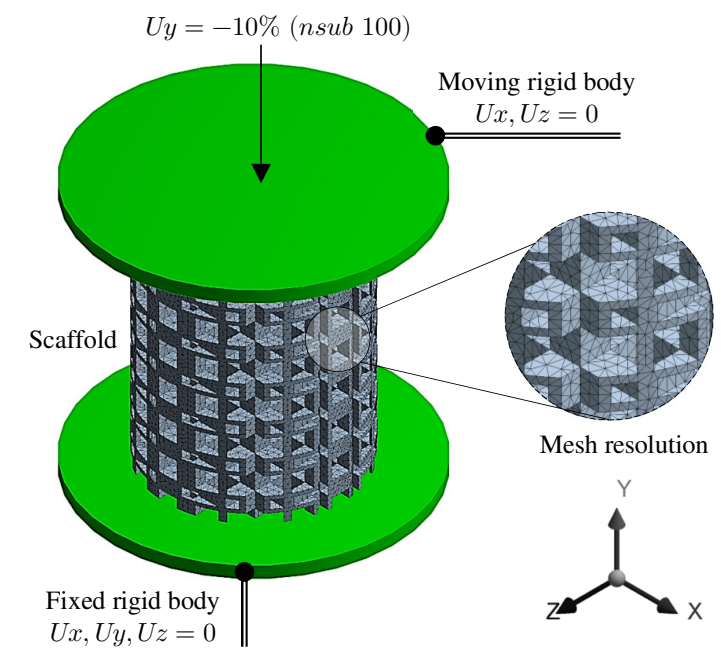

Fig. 4. FE model and associated boundary conditions used to simulate the mechanical behaviour of scaffolds.

The material parameters used for the numerical analysis were determined from tensile tests on fully dense SLM Ti6Al4V tensile test samples following BSENISO 6892-1:2016 [92]. The test samples were laser melted from the same Ti6Al4V bulk powder used to manufacture the scaffolds resulting in the respective properties listed in Table 2. The test was conducted at a crosshead displacement rate of $0.01 \mathrm{~mm} / \mathrm{s}$.

Table 2. Material properties of Ti6Al4V used for the finite element structural analysis.

\begin{tabular}{ll}
\hline Material property & Value \\
\hline Elastic modulus $\left(E_{B}\right)$ & $104.8(\mathrm{GPa})$ \\
Yield strength $\left(\sigma_{y(B)}\right)$ & $860(\mathrm{MPa})$ \\
Poisson's ratio $(\nu)$ & 0.3 \\
Density $\left(\rho_{B}\right)$ & $4428.78\left(\mathrm{~kg} / \mathrm{m}^{3}\right)$ \\
\hline
\end{tabular}


Mesh refinements were carried out using a mesh sensitivity analysis resulting in the number of finite element nodes and elements as listed in Table 3 at a maximum and minimum element size of 0.002 and $0.0015 \mathrm{~mm}$ respectively. The global elemental matrix was solved using an eightcore i7 CPU at $3.40 \mathrm{GHz}$ assisted by $128 \mathrm{~GB}$ RAM resulting in a solution time of approximately 3 hours.

Table 3. Elemental and nodal distribution associated with the converged structural FE model.

\begin{tabular}{ccccccc}
\hline \multirow{2}{*}{ Parameters } & \multicolumn{7}{c}{ Scaffold Design } \\
\cline { 2 - 7 } & SC1 & SC2 & SC3 & SC4 & SC5 & SC6 \\
Elements & 996480 & 1941123 & 1295438 & 1712847 & 2139810 & 752645 \\
Nodes & 3356756 & 4424839 & 3876420 & 4178037 & 4406290 & 1249012 \\
\hline
\end{tabular}

\subsection{Scaffold manufacture}

All the scaffolds were manufactured using an EOS M290 Selective Laser Melting machine (laser spot $80 \mu \mathrm{m}$ ) using a $30 \mu \mathrm{m}$ layer thickness. Ti6Al4V with a density of $4430 \mathrm{Kg} / \mathrm{m}^{3}$ featuring a chemical composition as listed in Table 2 was used. The material is composed of a mixture of Body-Centred Cubic $(\beta)$ and Hexagonal Close-Packed $(\alpha)$ phases [93-95]. Inhouse experimental tests on fully dense (99.9\%) standard tensile test coupons returned an E of $104.8 \mathrm{GPa}$.

Table 4. Chemical composition of the material used.

\begin{tabular}{lllllllll}
\hline Material (\%) & Al & V & C & Fe & O & N & H & Ti \\
\hline Ti6Al4V & $5.5-6.5$ & $3.5-4.5$ & $<0.08$ & $<0.25$ & $<0.13$ & $<0.05$ & $<0.012$ & Bal. \\
\hline
\end{tabular}

The EOS M290 belongs to a class of Powder Bed Fusion (PBF) technology [96] as classified by ISO/ASTM 52900:2017 [97] featuring a 400 W Gaussian Beam CW laser. SLM was carried out by modulating the laser power to $175 \mathrm{~W}$ at a scan speed of $1250 \mathrm{~mm} / \mathrm{s}$. A $67^{\circ}$ continually rotated hatching methodology in $x$ and $y$ as chosen as it delivered the most repeatable parts. An atomisation process was carried out on the powdered material which resulted in spherical particle sizes of 10 to $45 \mu \mathrm{m}$.

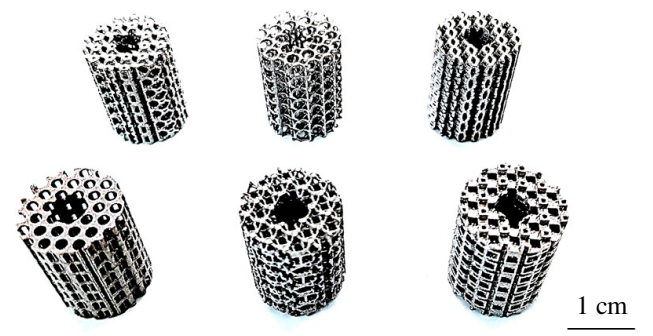

Fig. 5. Additively manufactured cylindrical scaffold.

The titanium base plate was heated to a uniform $35{ }^{\circ} \mathrm{C}$ before commencing the laser melting process. The SLM was then carried out using infill and stripes with a stripe width of $5 \mathrm{~mm}$ followed by infill scans. This method delivered a prototype of $99.98 \%$ material density. The melt 
chamber featured an argon-based environment maintained at a 0.1 to $0.13 \%$ Oxygen. Postprinting, the scaffolds were heat-treated for three hours at $650{ }^{\circ} \mathrm{C}$. Accordingly to Vrancken et al. [98], the effect of heat treatment on design porosity is negligible. After heat treatment, submerged Wire Electro-Discharge Machining (WEDM) was used to remove the scaffolds resulting in the respective prototypes presented in Fig. 5.

\subsection{Mechanical testing}

The Zwick-1474 universal materials testing machine in combination with a Nikon high definition video capturing device was used as the test rig as shown in Fig. 6 . The test machine featured a maximum load capacity of $100 \mathrm{kN}$. The calibration of the test right was carried out following BSENISO 7500-1 [99] and verification tests on standard samples were performed. Uniaxial compression was then carried out to study the behaviour of six different scaffolds following BSENISO 13314 [100].

The tests were conducted at room temperature and the scaffolds were compressed to plastic failure. The compression was carried out at a $0.01 \mathrm{~mm} / \mathrm{s}$ quasi-static crosshead movement at an $80 \mathrm{kN}$ force threshold and a $15 \%$ strain limit. The role of the threshold $(80 \mathrm{kN})$ and deformation values ( $15 \%$ strain) is to prevent the platens of the test instrument from colliding in the event of an abrupt failure. The video capturing device was automatically programmed to start and stop at the beginning and end of each test respectively.

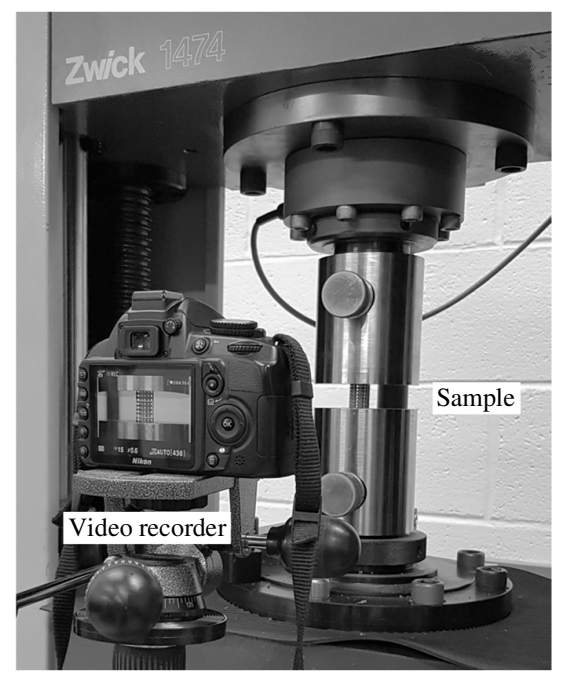

Fig. 6. Experimental test rig used for uniaxial compression of the SLM scaffold prototypes.

While the plastic behaviour is the scaffolds are insignificant [101] from a biomedical point of view, the data is crucial to characterise the failure modes associated with the scaffold geometry and porosity. 'TestXpert 2' data logger was used to record the force-displacement $(f-\delta)$ and stress-strain $(\sigma-\varepsilon)$ data during compression. The effective elastic modulus (E) characterising the stiffness of the scaffolds were then derived as the slope of the linear $\sigma-\varepsilon$ curve. The yield strength $\left(\sigma_{y}\right)$ was characterised as the stress at which the strain linearity deviates by $0.2 \%$. 
While the young's modulus characterised the stiffness the $\sigma_{y}$ characterised the strength of the scaffold.

\section{Results and observations}

\subsection{Permeability}

An effective bone scaffold design has to bring together a multitude of properties such as biocompatibility, porosity, stiffness, strength and permeability [102]. Permeability is related to the amount and type of porosity and determines the scaffold's effectiveness in both waste removal and nutrient supply necessary for bone growth [103]. While a lower permeability is ineffective for bone growth due to insufficient waste removal and nutrient supply, equally disadvantageous is a higher permeability resulting in cell washout [104,105]. Accordingly, the ideal permeability necessary for a scaffold lies closer to the bone that is being replaced which in this case was found to lie between 0.5 and $5\left(10^{-8} \mathrm{~m}^{2}\right)[83,106]$.

A repeating UC strategy in scaffold design allows for critical consideration of both structural and flow properties at the fundamental design stage. Accordingly, the permeability of the six UCs was assessed through CFD using the finite volume method. To validate the CFD methodology, the analysis was carried out on Rec-L-85 [90] model proposed by Ali and Sen [90]. Comparing the permeability values as shown in Table 5, a percentage difference of $2.17 \%$ was observed resulting in excellent agreement.

Table 5. Validation of the CFD methodology with literature.

\begin{tabular}{llll}
\hline Parameter & Validation & Ali and Sen [90] & \% Difference \\
\hline $\mathrm{K}\left(10^{-8} \mathrm{~m}^{2}\right)$ & 2.73 & 2.79 & $2.17 \%$ \\
\hline
\end{tabular}

The surface pressure contours for all the six UCs are shown in Fig. 7 where a pressure drop from the inlet to the outlet can be observed for all UCs. Other than the inlet, the concentration of high pressure can be seen around opposing flat surfaces, which are comparatively less hydrodynamic (UC1, UC3 and UC4). Overall, the most complex pressure pattern was exhibited by UC2 primarily due to the expanding and narrowing geometry coupled with comparatively low porosity $(73.31 \%)$.

Investigating the velocity of a DMEM fluid across as shown in Fig. 8, significant variation was observed in and around the designs. The flow velocity close to UC surfaces was lower than the values of the surrounding area. This was expected due to the influence of surface friction and is a common phenomenon observed in fluid dynamics. Evaluating the design influence on the velocity vector, UC6 was found to have the least effect primarily because of the large throughflow open porosity followed by UC4. Consequently, the average velocity of flow through the cavities was found to be higher for these two designs. 


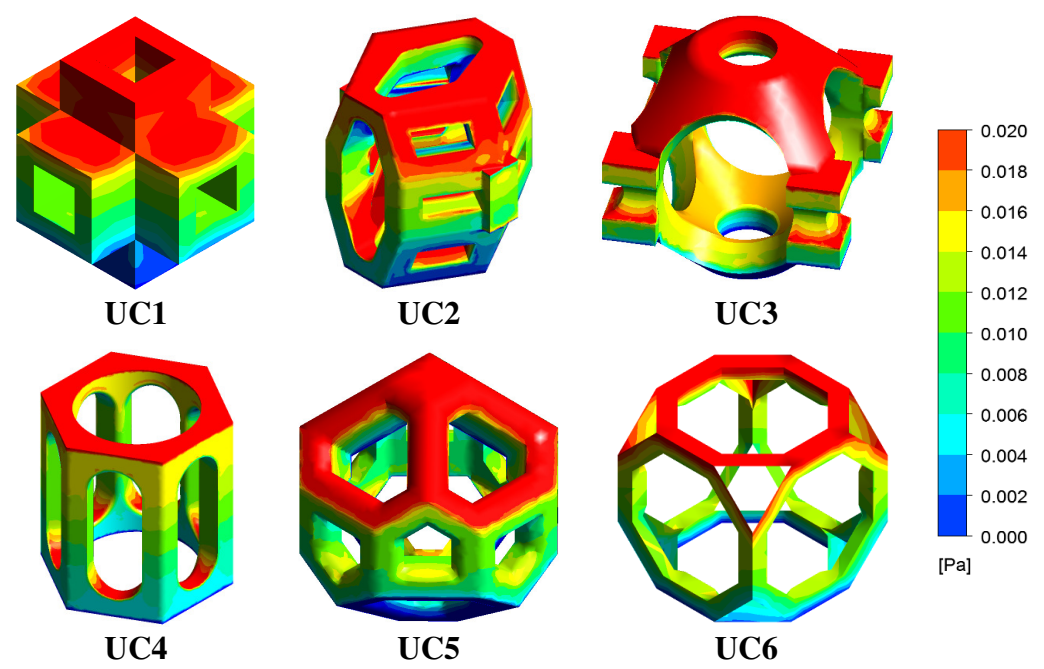

Fig. 7. Flow-induced pressure distribution across the unit cell surfaces observed from CFD analysis.

A high permeability combined with high velocity through the pores may result in cell washout resulting in poor cell migration. On the other hand, a significant flow declaration in the pores was exhibited by UC1 $(\sim 0.1 \mathrm{~mm} / \mathrm{s})$ followed by UC3 $(\sim 0.2 \mathrm{~mm} / \mathrm{s})$ and UC5 $(\sim 0.4 \mathrm{~mm} / \mathrm{s})$. While the reason for the flow deceleration is the narrow pores and lower porosity for UC1; the complex design and shape gradients of the pores are the contributory factor when it comes to UC3 and UC5 thus signifying a higher influence of the pore geometry.

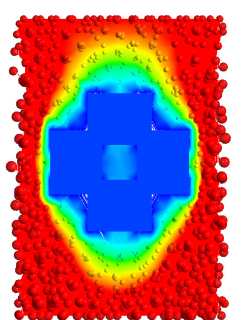

UC1

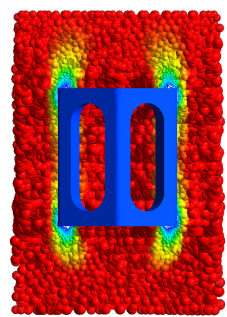

UC4

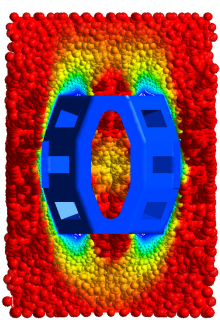

$\mathrm{UC2}$

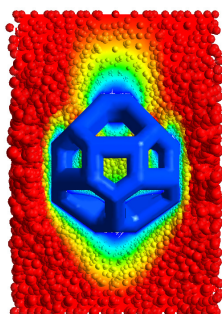

UC5

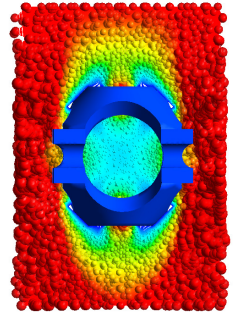

UC3

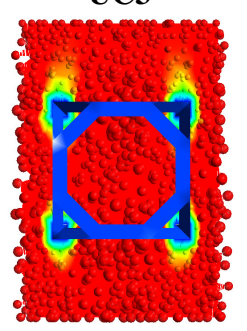

UC6

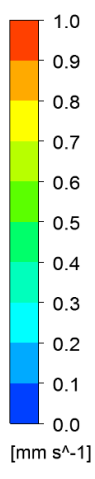

Fig. 8. Velocity profile resulting from the numerically modelled DMEM travelling across the central plane.

Lower velocity [107] and higher surface friction can increase the chances of osteoblast attachment to the scaffold surfaces as a result of the longer time [21]. The flow velocity within a scaffold is also associated with the effectiveness of the pores in aiding both mass transport and cell attachment [108]. Accordingly, it can be considered the second most influential flow parameter followed by permeability. Therefore, a scaffold featuring permeability closer to the bone being replaced in addition to featuring a good balance of low and high flow rate maybe be beneficial. 
Between the designs tested, a balance of flow velocity in addition to permeability that is closer to the host bone was exhibited by UC2 at a porosity of $74.31 \%$.

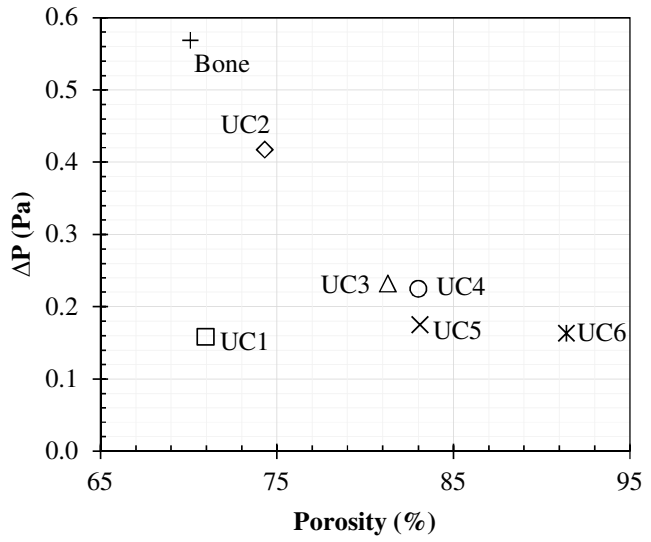

(a)

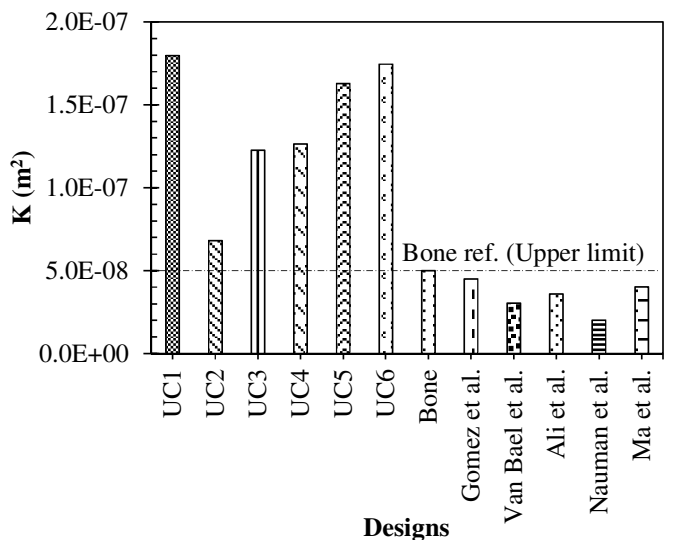

(b)

Fig. 9. Flow performance associated with pore geometry where (a) shows the pressure drop across the unit-cell designs and (b) the permeability in comparison to the bone being replaced and attempts from literature.

Analysing the pressure-drop $(\triangle \mathrm{P})$ and permeability $(\mathrm{K})$, it can be seen that porosity alone is not an indication of pressure drop (Fig. 9a). On the other hand, less obstruction to flow and straight pore structure was found to deliver a lower pressure drop. The highest-pressure drop was exhibited by UC2 $(0.417 \mathrm{~Pa})$ which featured the most complicated flow path with a combination of large and small pore shapes. The lowest was exhibited by UC1 followed by UC6 and UC5 at $0.158,0.163$ and 0.175 respectively. Overall, a $90 \%$ difference in $\triangle \mathrm{P}$ was observed between $\mathrm{UC} 1$ and $\mathrm{UC} 2$ (lowest and highest) at a $\sim 4.5 \%$ difference in porosity. This shows that the desired pressure drop can be obtained by careful modelling the flow path and is not limited to the overall porosity of the structure itself. The observations can be related to Knychala et al. [109], who also observed an increased significance of pore shape when it comes to the development of bone marrow tissues.

Looking at permeability, many attempts in literature can be found to reach $\mathrm{K}$ values closer to that of bone with Gomez et al. [45], Van Bael et al. [21], Ali and Sen [90], Nauman et al. [110] and Ma et al. [23] achieving significant closeness as shown in Fig. 9b. For the tibial section being replaced, the permeability of the bone is approximately $5 \times 10^{-8} \mathrm{~m}^{2}$ (unweighted avg.), consequently, attempts have been placed to design UCs that can perform above the required permeability. As shown in Fig. 9b, all UCs delivered K values higher than the bone that is being replaced. A slightly higher $\mathrm{K}$ can account for the potential variation in geometry due to the stair-step effect associated with the SLM process. Out of the six designs, UC2 was found to be the closest to bone at $6.81 \times 10^{-8} \mathrm{~m}^{2}$, the furthest performance was exhibited by $\mathrm{UC} 1$, followed by UC6 and UC5 at $0.18 \times 10^{-8}, 0.18 \times 10^{-8}$ and $0.16 \times 10^{-8} \mathrm{~m}^{2}$.

Studies on the influence of geometrical shapes in enhancing permeability are scarce; the investigations were primarily focused on pore size $[111,112]$ as opposed to shape. However, the 
results of this study show that the role of geometrical design is significant on permeability, which calls for greater attention while designing bone scaffolds. It is evident that the pore shape and surface curvatures (UC2) strongly influence the permeability of the scaffold. Since recent advances in AM have enabled enhanced design freedom, the potential for exploiting geometrical design to enhance bone tissue regeneration is greater than ever.

\subsection{Ashby's criterion and mechanical performance}

According to Ashby's criterion [64], repeatable cellular structures can be divided into either stretch or bend dominated depending upon the type and number of beams and joints. While stretch dominated behaviour exhibits failure due to elongation of the cell walls, bending of cell walls dominate the other criteria [113]. Similar to commercial cellular materials like metallic foams [114], honeycombs and lattice trusses [115] all the six UCs considered in this study are bending-dominated. Consequently, the theoretical effective elastic modulus $\left(E_{t h r}\right)$ and compressive strength $\left(\sigma_{y(t h r)}\right)$ can be related to their relative densities $\left(\rho_{r}\right)$ using Eqn. (3) and (4) respectively:

$$
\begin{gathered}
E_{t h r} \approx E_{B} \rho_{r}{ }^{2} \\
\sigma_{y(t h r)} \approx \sigma_{c(B)} \rho_{r}{ }^{\left(\frac{3}{2}\right)}
\end{gathered}
$$

where $E_{B}$ and $\sigma_{y(B)}$ are the Young's modulus and stress at yield of the bulk material, which in this case was experimentally evaluated as listed in Table 2. Evaluating the theoretical performance of the scaffold designs based on Ashby's criterion as shown in Fig. 10, scaffold SC1 showed the highest effective elastic modulus and compressive strength of 10.42 GPa (Fig. 10a) and $152.30 \mathrm{MPa}$ (Fig. 10b) respectively, which is representative of the low porosity.

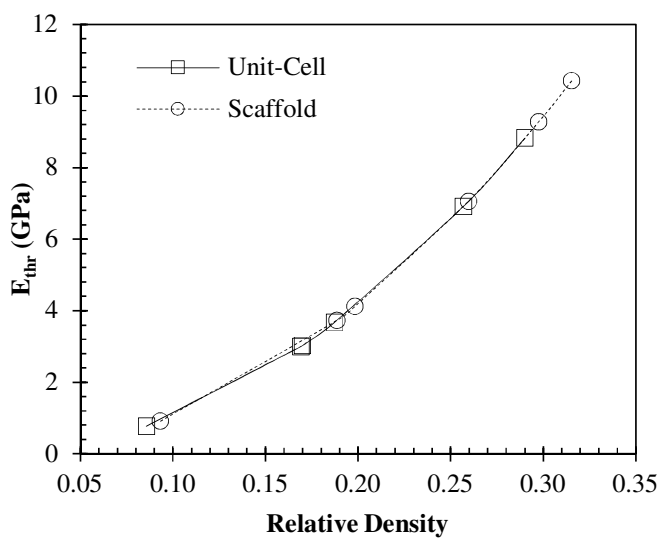

(a)

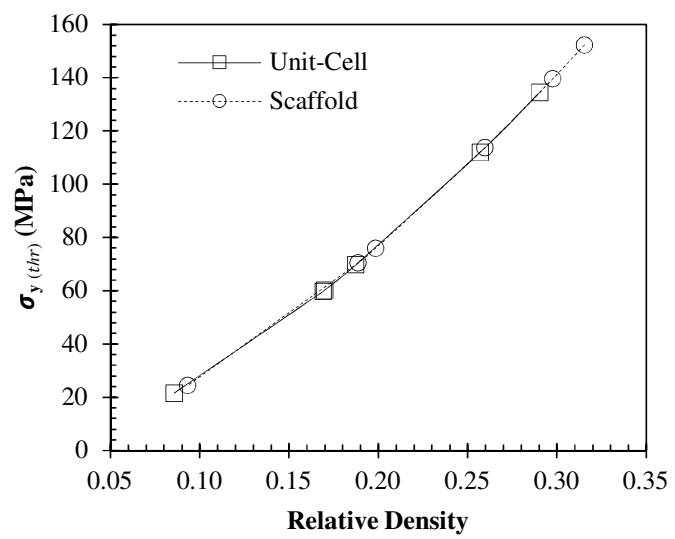

(b)

Fig. 10. Theoretically evaluated (a) effective elastic modulus $\left(E_{t h r}\right)$ and (b) compressive strength $\left(\sigma_{y(t h r)}\right)$ for all the six unit-cells and respective scaffolds using Ashby's bend dominated criterion.

The lowest performance was exhibited by SC6 at $0.91 \mathrm{GPa}\left(E_{t h r}\right)$ and $24.42 \mathrm{MPa}\left(\sigma_{y(t h r)}\right)$, which is representative of their high porosity. Comparing the performance between the unit cells and scaffolds (Fig. 10a and 10b), the resulting $E_{t h r}$ and $\sigma_{c(t h r)}$ show a similar trend in 
performance. Therefore, using theoretical characterisation following Ashby's criterion SC1 showed the highest stiffness followed by SC2. In summary, the theoretical modulus of all the scaffold designs fall within the lower spectrum of the tibial cortical bone at 0.91 to $10.41 \mathrm{GPa}$ [116-118].

\subsection{Elastic-plastic performance}

The compressive $\sigma-\varepsilon$ curve of the SLM manufactured scaffolds and the respective numerical prediction using the FEM is shown in Fig. 11. Generally, the $\sigma-\varepsilon$ curve of cellular structures tends to show three characteristic regions which in its entireness describes the elastic and plastic structural performance [119]. The first characteristics regions can be speared into linear and nonlinear elastic deformation, where a proportional $\sigma-\varepsilon$ relationship is followed by a non-linear region ending in a peak stress value referred to as the ultimate strength $\left(\sigma_{u}\right)$ [120]. This is usually

followed by a drop-in stress to the plateau region where stress fluctuations or serrations maybe observed [121]. Further compression results in a densification region followed by a plateau where the rises in stress can be primarily attributed to the interaction of the crushed material. However, the occurrence of the densification region depends largely on the type and porosity of the cellular structure and associated boundary conditions [122].

Evaluating the results as shown in Fig. 11(a-f), all the scaffolds showed both elastic and plastic regions. However, scaffolds SC4 and SC6 showed total collapse following the $\sigma-\varepsilon$ plateau representing limited involvement from subsequent cellular layers. This is due to the long straight vertical beams that forms the primary load bearing component of the unit-cell (UC4 and UC6). While the said UC geometries limits the lateral strain due to the limited involvement of crossbeams; the phenomenon in combination with high porosity is the reason for catastrophic failure. Nevertheless, SC4 showed both high yield $\left(\sigma_{y}\right)$ and ultimate strength $\left(\sigma_{u}\right)$ of 246 and $284 \mathrm{MPa}$, respectively (Fig. 11d).

In contrast, the performance of SC6 (Fig. 11f) was significantly lower at $\sigma_{u}$ at $46 \mathrm{MPa}$ primarily due to the high porosity (90.69\%). Looking at the numerical results, both SC4 and SC6 showed excellent agreement up to the yield strength which was the primary objective of the numerical model. Prediction of the post-yield behaviour was limited to the bilinear isotropic strain hardening material model considered for the analysis as the post-yield was modelled perfectly plastic. For biomedical application, the stiffness and strength (stress at failure) are the key aspects for design consideration as scaffolds are expected to withstand failure during its lifetime [123-125].

Scaffolds SC1 and SC2 (Fig. 11a and 11b) showed similar ultimate strength despite the vastly different UC designs. However, this can be attributed to the relatively close porosity featured by these two designs at a difference of only $2.5 \%$ (SC1 vs. SC2). For $\sigma_{y}, \mathrm{SC} 2$ was inferior to $\mathrm{SC} 1$ due to the interaction of the deformed material facilitated by the complex pore geometry UC2. 
This is accurately captured in the numerical prediction where the point of yield crosses the experimental data as shown in Fig. 11b. Overall, for these two scaffolds, the post-yield behaviour shows a staged failure with comparable $\sigma-\varepsilon$ curves.
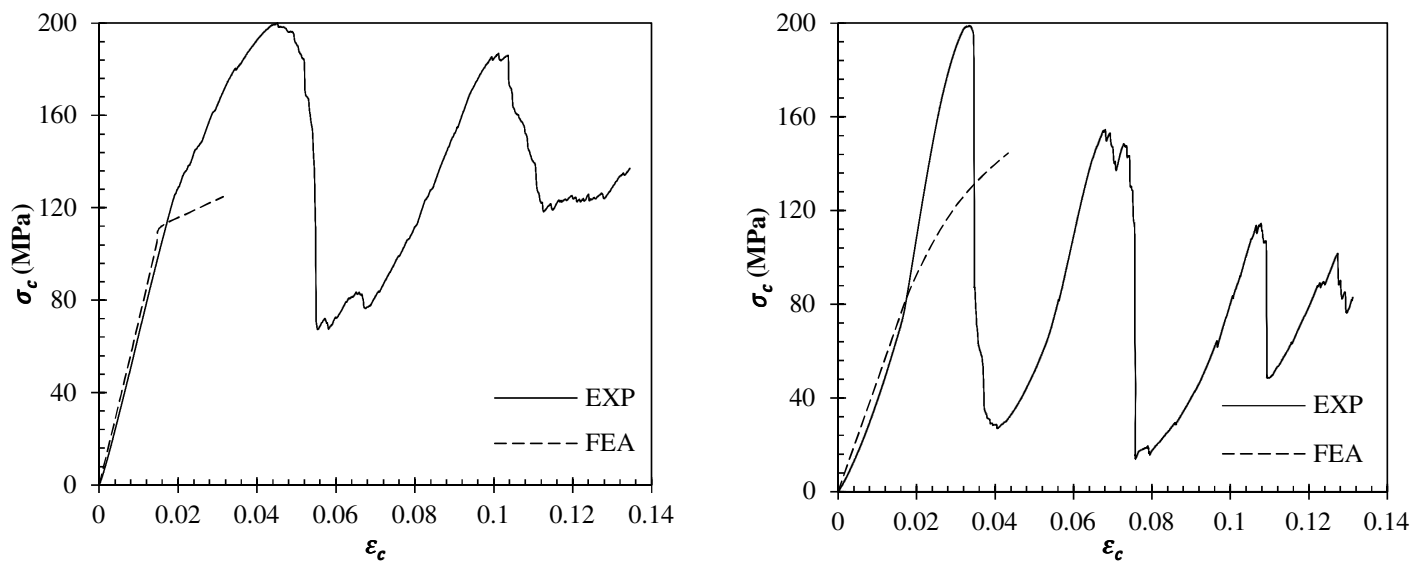

(a) $\mathrm{SC} 1$

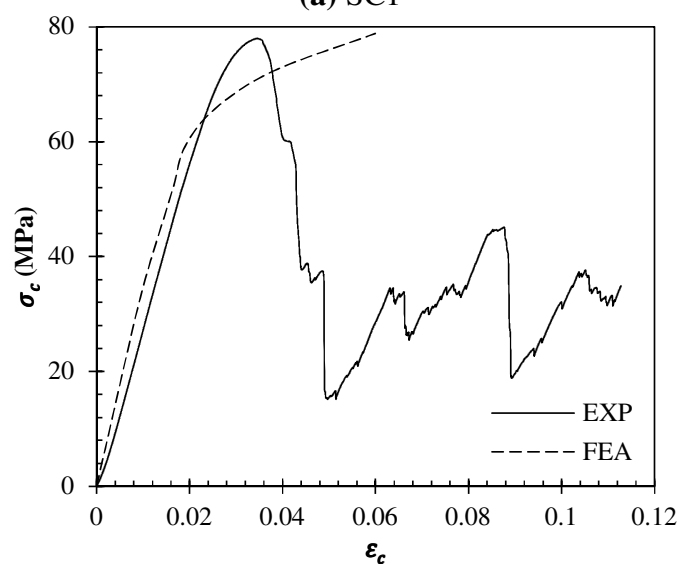

(b) $\mathrm{SC} 2$

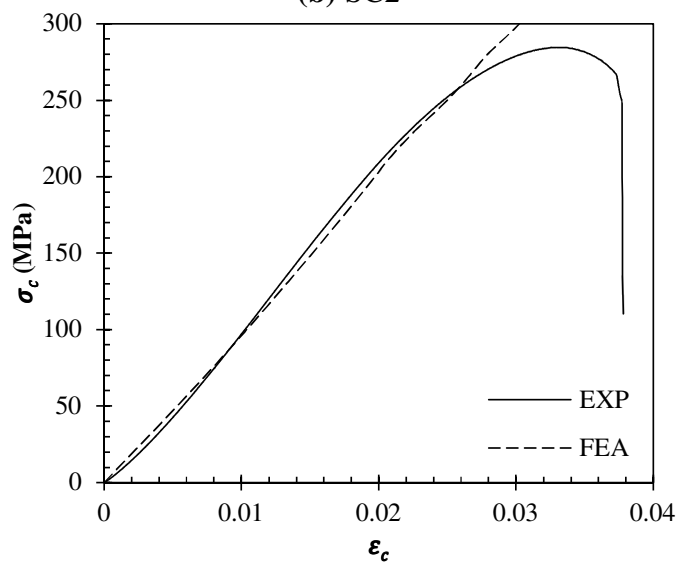

(c) $\mathrm{SC} 3$

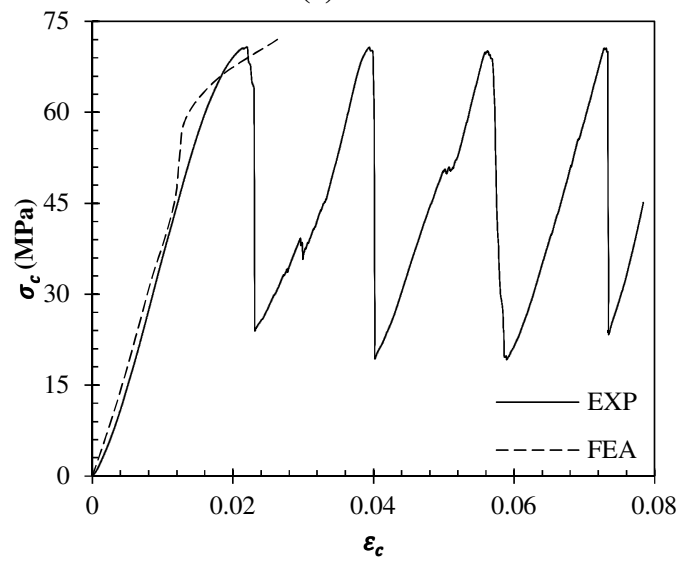

(e) SC5

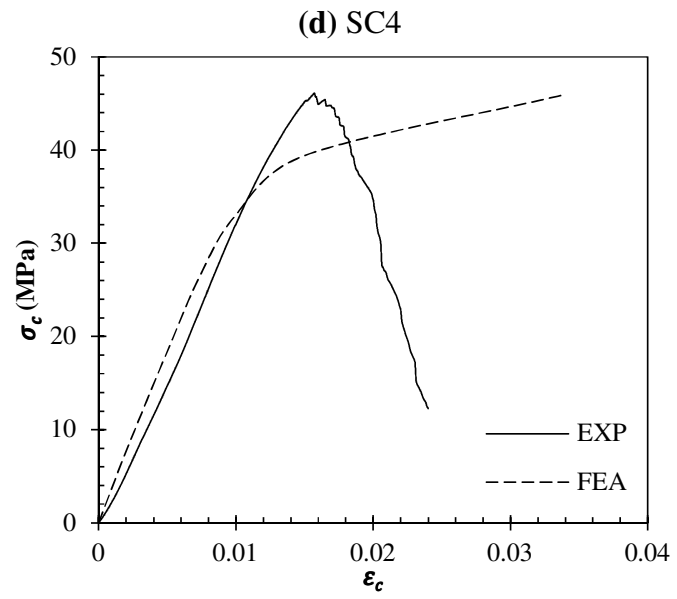

(f) SC6

Fig. 11. Stress-strain curve for all the six scaffolds designs (a to f) compared against the respective numerical predictions using the Finite Element Method (FEM).

Crush bands representative of typical brittle cellular structures was observed for both SC1 and $\mathrm{SC} 2$, with the former exhibiting a higher crush period with minimal difference in stress amplitude 
due to the uniform pore size within the UC. In comparison, SC2 showed a lower crush period with decreasing stress amplitude as a result of the higher interaction between the cellular layers. In addition, the reduction in strength was more abrupt for SC2 resulting in lower serration valleys in comparison to SC1 where the crush bands were comparatively wider and shallower. For both these scaffolds, the numerical predictions seem to closely follow the experimental behaviour accurately identifying both $\mathrm{E}$ and $\sigma_{y}$.

Behaviour of SC3 (Fig. 11c) was representative of a reticulated mesh structure with repeating lattices $[126,127]$. According to Santorinaios et al. [128], this can be identified by the dominant first plastic peak followed by relatively smaller crush bands where the overall load-bearing capacity is significantly less. The reticulated lattice-like behaviour meant that the associated numerical behaviour was able to predict both the elastic and plastic regions up to the first peak accurately.

On the contrary, the behaviour of SC5 (Fig. 11e) was representative of a stochastic structure $[129,130]$ despite featuring a repeating UC. This is due to the presence of varying pore sizes featured in UC5 which when assembled represent a metallic foam-like structure featuring multiple pore sizes throughout the scaffold. According to Maliaris and Sarafis [131], stochastic foams are often heterogeneous resulting in distinctive layers of strong and weak regions. This results in the initial crush bands representing the systematic failure of the weak regions while the overall stability of the scaffold is preserved by the strong regions. While the weak regions reduce the overall mechanical performance, subsequent crush bands can often take a higher load resulting in $\sigma_{u}$ close to the first peak as can be seen from Fig. 11e.

Fig. 12 shows the accuracy of the FE numerical model in predicting the stiffness (E) and strength $\left(\sigma_{y}\right)$ of the scaffolds. When compared to physical test data under identical conditions similar trend in results can be observed for both cases considered. Nevertheless, a highest difference of $19.58 \%$ in effective elastic modulus was exhibited by SC3 between the two methods. For yield strength, the least accurate prediction was for SC5 followed by SC6 at a difference of $24.72 \%$ and $18.38 \%$ respectively. On the other hand, the closest results between the two methods were found for SC1 followed by SC2 at a difference of $3.46 \%$ and $7.21 \%$ for $\mathrm{E}$ and $\sigma_{y}$, respectively.

While the numerical model identified the trend in mechanical performance with reasonable accuracy as established in Fig. 11 and 12, further refinements are necessary. The difference between the numerical and experimental data can be primarily attributed to the influence of the SLM additive manufacturing technique. It is well documented that [25,132-136] SLM variation in geometry due to the stair-step effect and partly fused powder on the surface, the effect of this is increasingly significant for porous and geometrically complex thin-walled structures such as the ones presented in this study. While the experimental data accounts for all irregularities, the numerical models assume an idealised structure based on CAD that is homogenous and free or 
any surface irregularities. Furthermore, the rough surface finish, which is also a salient feature of SLM samples can significantly influence the mechanical behaviour at comparable beam and wall thickness.

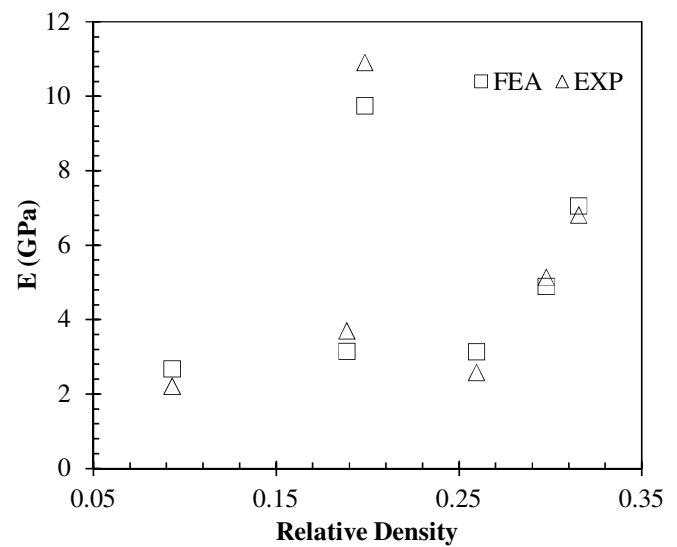

(a)

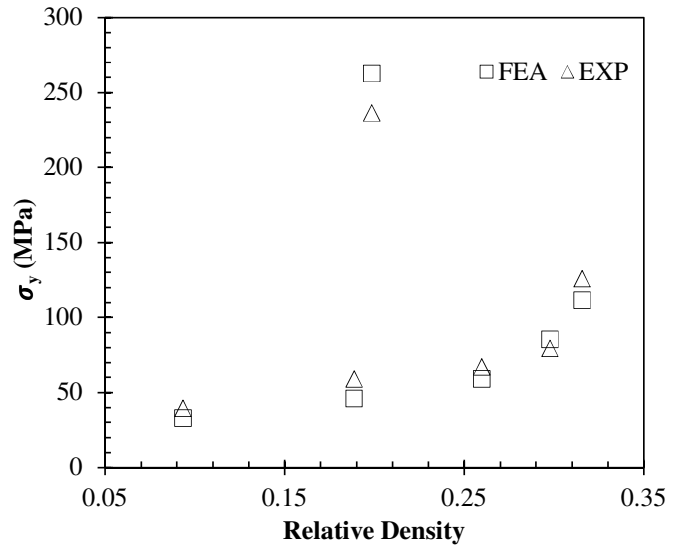

(b)

Fig. 12. Comparison of finite element and physical test results for (a) effective elastic modulus and (b) bearing strength.

How well the FE model can predict the physical behaviour often depends on the accuracy of the macroscopic material model employed $[137,138]$. For the presented analysis, the material properties were obtained from tensile tests carried out on fully dense (optimum SLM parameters) laser melted Ti6Al4V which is the standard practice [139-142]. However, a more effective alternative could be the use of slightly porous cylindrical cubes under compression to derive the material properties. Nevertheless, the best case of $19.58 \%$ and $24.72 \%$ for E and $\sigma_{y}$ respectively still shows a good agreement; a difference higher than $30 \%$ [101] to four folds $[60,143,144]$ is often reported for additively manufactured porous parts.

\subsection{Failure mode analysis}

Morphology of individual cell structure and associated connections influences the scaffold's structural performance. Fig. 13 shows the selected still frames from the video recorded under quasi-static compression with a view to characterising the plastic deformation and the collapse of the cellular structure. Chosen frames correspond to the initial almost not compressed state; the moment of first failure followed by $75 \%$, and $100 \%$ plastic deformation. From the deformation, it is clear that as the scaffold porosity increases the strain at catastrophic failure (sudden reduction in $80 \%$ load carrying capacity) decreases with the lowest strain to failure exhibited by SC6 at a porosity of $90.69 \%$ (Fig. 13f).

The only exception to this trend is the performance of SC5 (Fig. 11e and 13e) which showed sustained and consistent strain at each crush band. This is due to the stochastic nature of the SC5 structure; meaning failure is not due to the progressive nature from the single weakest link 
instead dominated by multiple weaker links. This is further reflected in the fully deformed frame of the respective scaffolds (Fig. 13e) where the compression is uniform. This means that SC5 can sustain multiple failure layer matching the first peak stress before the total structural collapse. Four failed layers were observed, each capable of sustaining the same ultimate stress before the structure collapsed. A slight lateral but uniform expansion of the structure was also observed showing that the shape of UC influences the scaffold behaviour in a very pronounced way.

Scaffolds SC1 and SC3 feature relatively uniform and even distribution of pore sizes resulting in failure through the formation of crush bands (Fig. 13a and 13c). Moreover, these bands can be seen to propagate perpendicular to the loading direction. Furthermore, these two scaffolds also exhibit fracture initiation along the same region and propagation laterally through the crosssection of the scaffold resulting in catastrophic failure. A similar observation was made by Surmeneva et al. [19] when studying the deformation of graded repeating structures with around $65 \%$ porosity. In general, the failure pattern resembles a case where multiple pore sizes are arranged regularly causing a disparity in the axial stiffness.
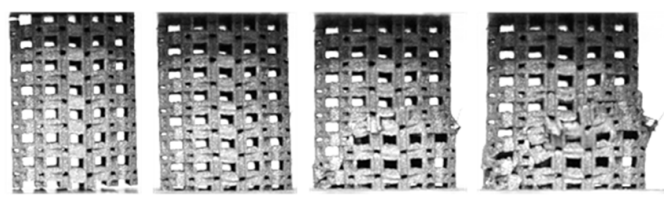

(a) $\mathrm{SC} 1$
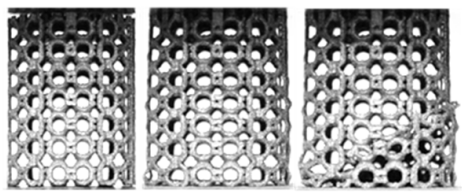

(c) $\mathrm{SC} 3$
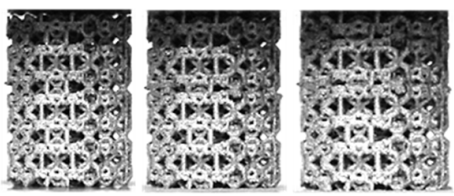

(e) SC5
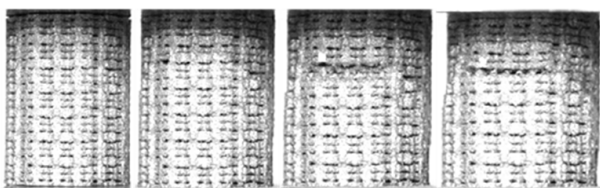

(b) $\mathrm{SC} 2$
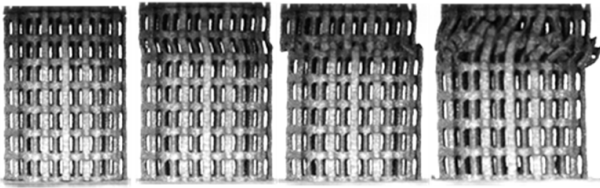

(d) $\mathrm{SC} 4$
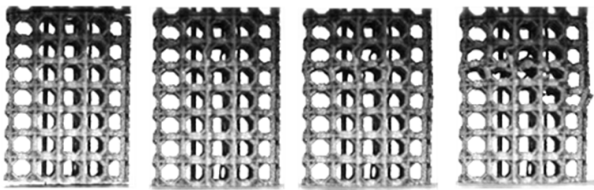

(f) SC6

Fig. 13. Deformation and failure modes associated with the six scaffolds under uniaxial compression.

SC2 showed barrel-shaped bulging (Fig. 13b) a feature that can be attributed to the increased lateral resistance facilitated by the convex walls of the associated UC. Furthermore, the layer interaction due to the gradually decreasing pore size is the reason for the two distinctive slopes on the run-up to the ultimate stress (Fig. 11b). Furthermore, the failed sample shown in Fig. 13b resembles thin wall buckling. The failure occurred per lattice layer where two complete layers deformed one after the other. Nevertheless, the load-bearing capacity was found to reduce 
gradually and consistently as the crush bands progressed through the structure until an $80 \%$ load reduction took place.

In comparison, the failure of SC4 and SC6 was abrupt with a sudden reduction in $80 \%$ of the load-carrying capacity following the first peak. While this was expected due to the localised stress concentration and high porosity facilitated by the UC designs; the failure was representative of a brittle classification. For SC4, the failure started as a localised failure on the $2^{\text {nd }}$ layer which shifted the entire layer towards the side resulting in catastrophic failure. Hence, the deformation mode can be attributed to the highly stiff axial and lateral meshes. When stressed across the build layers (vertical) [145], the deformation response was highly brittle exhibiting a lower strain to failure. For SC6, the primary failure mode is localised beam buckling at single UC level which quickly travels across the layer due to the load imbalance leading to catastrophic failure (Fig. 13f). The failure is typical of highly porous cellular structures featuring thin beams [146].

\subsection{Influence of stress concentration}

The theoretical analysis showed that stiffness and strength of the scaffold varies with the square of the relative density $\left(\rho_{r}\right)$. However, both the experimental and FE result revealed deviation from theoretical with SC4 exhibiting both the highest stiffness and strength despite featuring a porosity of $80.17 \%$ (Fig. 12). Consequently, it is established that the geometry of the unit cell has a higher influence on the mechanical performance of the scaffold and an enhanced understanding of the stress distribution is required to derive design guidelines. Furthermore, when it comes to cellular structures. every aspect of their mechanical performance and failure are dependent on the concentration of stress facilitated by the geometry as opposed to relative density [147].

Following the works of Salimon et al. [148], a certain dependence of $\sigma_{c}$ was established with $\rho_{r}$ for stochastic structures (SC5). Even for this scaffold, some discrepancies were observed between theoretical and experimental results, which is likely to be contributed by the stress concentration. Overall, it is well established $[48,149,150]$ that certain designs are more prone to stress concentration and may lead to an early onset of plasticity failure. However, any correlation of this to stiffness are still unknown when it comes to the performance of biomedical scaffolds in general. Furthermore, given that scaffold often require a high porosity $(>60 \%)$, identifying the stress concentration factor is crucial for the design of functional scaffolds.

Unlike experimental tests, the FE model provides a large set of data and the close validation allows it to be extended for further analysis. Accordingly, Fig. 14 shows the stress distribution within the scaffold which reveals the location of the stress concentration. A constant legend is used to aid visual identification of the best and worst cases for their respective stress profiles. The associated magnitude for $\sigma_{\max }$ can be identified from Fig. 15 for the respective porosities. 


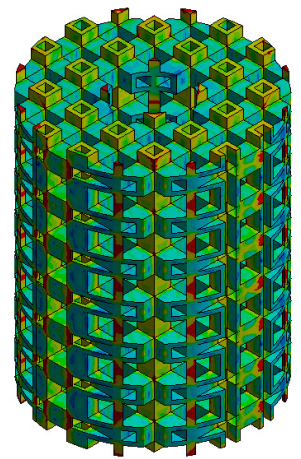

(a) SC1

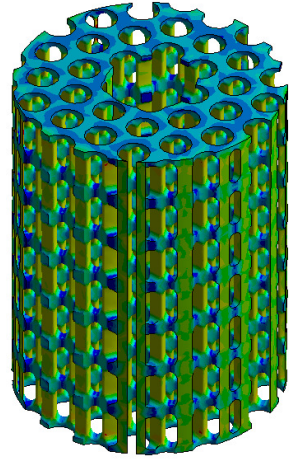

(d) SC4

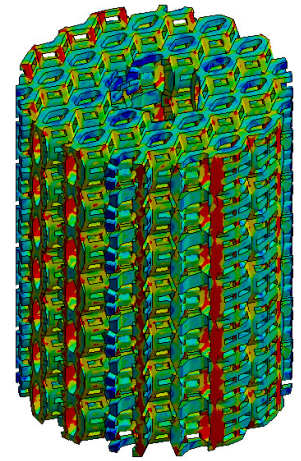

(b) $\mathrm{SC} 2$

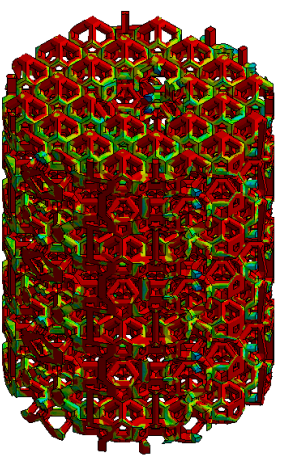

(e) $\mathrm{SC} 5$

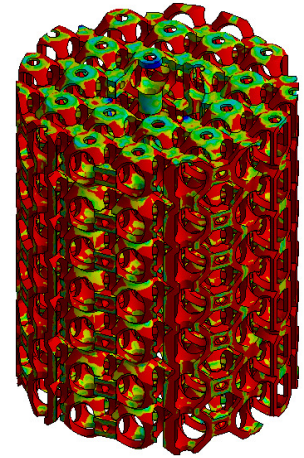

(c) $\mathrm{SC} 3$
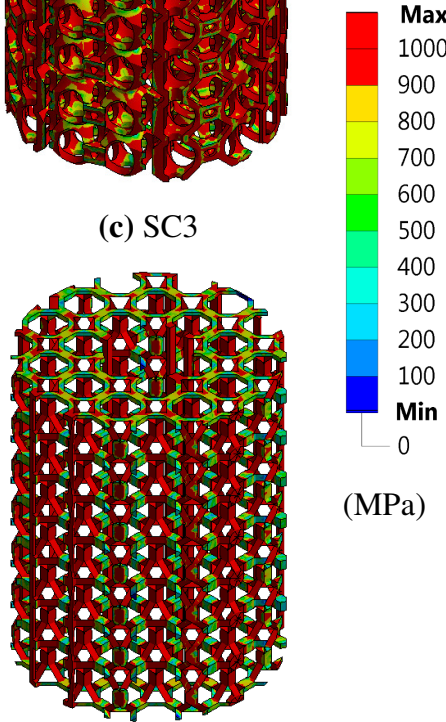

(f) SC6

Fig. 14. Stress distribution for the scaffold designs simulated using the finite element method under boundary conditions similar to experimental tests.

Evaluating the results, depending on the UC, there is a significant disparity in $\sigma_{\text {max }}$ experienced by the scaffolds. The highest stress concentration is exhibited by SC6 followed by SC5 and SC3. The lowest stress concentration with the most uniform stress distribution was exhibited by SC4 followed by SC1 and SC2. The resulting impact of the concentrated stress on the E and $\sigma_{y}$ of the scaffolds can be observed from Fig. 15a and 15b respectively.

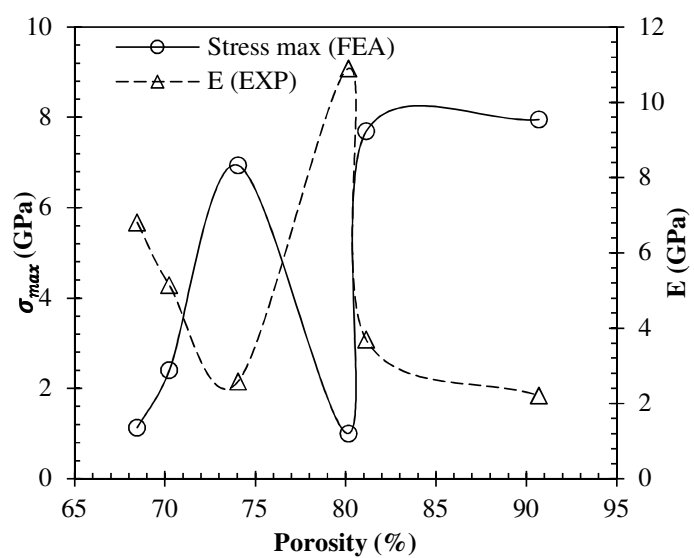

(a)

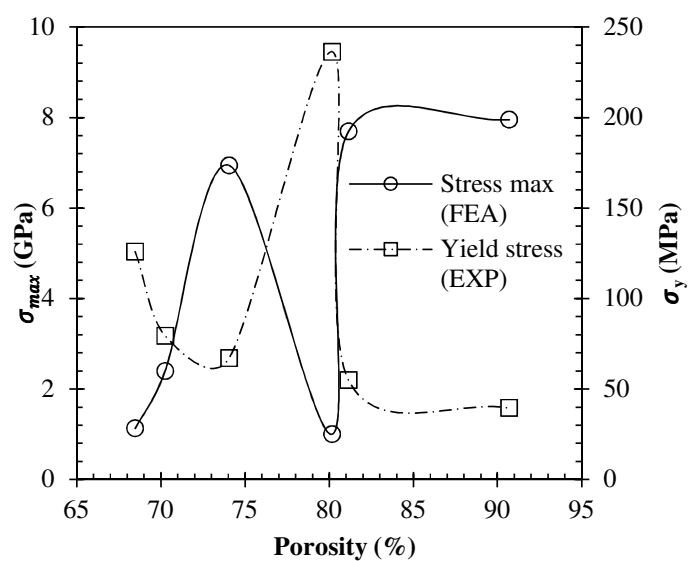

(b)

Fig. 15. Influence of finite element derived maximum stress $\left(\boldsymbol{\sigma}_{\max }\right)$ facilitated by the scaffold on (a) effective elastic modulus and (b) yield strength. 
When the scaffolds were compressed elastically (linear region of the stress-strain curve), the macroscopic stresses that are generated within the material is proportional to $\varepsilon$. Fig. 15 shows that the maximum stress as a result of stress concentration does not follow the power-law associated with relative density. Rather it depends primarily on the shape of the UC and the associated connection to adjacent UCs. Both the stiffness (Fig. 15a) and strength (Fig. 15b) exhibited by the scaffolds are inversely proportional to $\sigma_{\max }$. Consequently, the design that featured the highest stress showed the lowest E and $\sigma_{y}$. As a result, SC4 shows the highest stiffness and strength due to its lower stress concentration in comparison to other designs analysed.

Cellular structures can often be modelled as an equivalent macroscopic material where the performance is dictated by the nominal stress $(\tilde{\sigma})$ experienced by the macroscopic volume $[151,152]$. Accordingly, the stress concentration factor $\left(K_{t}\right)$ can be defined as the ratio of $\sigma_{\max }$ to $\tilde{\sigma}$. The factor $\left(K_{t}\right)$ as shown in Fig. 16 then becomes an useful parameter in identifying the most suitable UC for bone scaffolds, as it considered both the effective macroscopic and microscopic stress localisation [153].

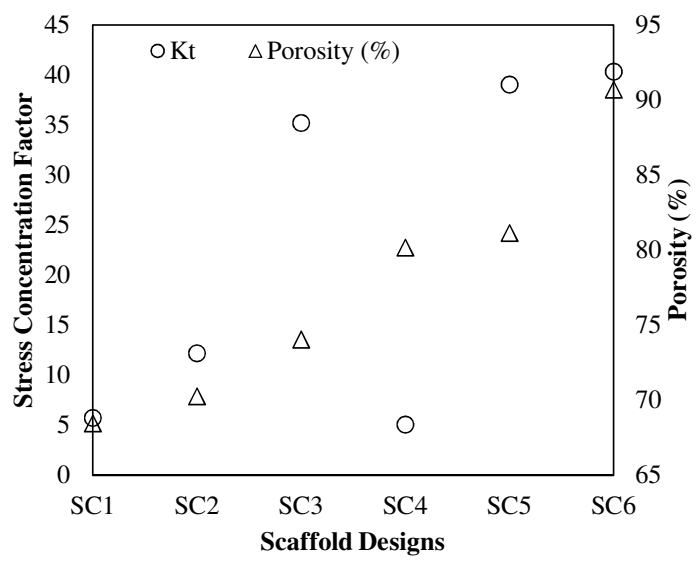

Fig. 16. Stress concentration factor and associated porosity of the scaffold designs considered.

Analysing the stress concentration factors shown in Fig. 16, SC4 exhibited the lowest $K_{t}$ of 5.07; meaning that the concentration of stress is five times the average nominal stress $(\tilde{\sigma})$, which is common for cylindrical and spherical pores [154]. The highest $K_{t}$ of 40.34 was exhibited by SC6 showing that the stress build-up in the porous mesh can be up to 40 times $\tilde{\sigma}$. Consequently, it can be regarded that $K_{t}$ is an important parameter to be considered in scaffold design. By carefully controlling the stress concentration, required stiffness and strength can be achieved at significantly high porosities. Furthermore, once $K_{t}$ is known, it is possible to have an indication of the onset of plasticity and potential failure from the equivalent macro-model [155]. This also contributes to the overall aim of deriving tissue engineering design guidelines allowing to reduce material mass while delivering compatible porosity, stiffness, strength and permeability. 


\section{Discussion}

Tissue-engineered scaffolds have the potential for repairing or replacing damaged bone for critical length defects [156-158]. In addition to offering structural stability, their function extends to supporting cell growth to either eliminate or compliment autologous and allogeneic bone grafts [159-161]. In this aspect, the major requirements for the scaffolds are biocompatibility, suitable pore size, volumetric porosity, permeability and compatible stiffness and strength to the bone that is being replaced. Although bio-ceramics [162-164] and polymers [165-167] are commonly used to make tissue scaffolds, their mechanical strengths are in most cases inadequate for critical length defects. Accordingly, porous biocompatible metallic structures with matched permeability, stiffness and strength are preferable [168]. This can prevent stress shielding and maladapted stress concentration that are often the causes of tissue loss and scaffold loosening, which are well-documented issues of inherently stiff metallic scaffolds [101,169-172].

This study presents six Ti6Al4V scaffolds (Fig. 2) designs with a view to improving the stiffness, strength and permeability at a porosity range of 68.46 to 90.69 (vol. \%). In doing so, the work attempted to identify suitable strategies that can be incorporated into high strength biocompatible materials to improve its functionality. The ideal ranges of permeability $(\mathrm{K})$, stiffness (E) and strength $\left(\sigma_{y}\right)$ for the scaffolds depend on the host bone being replaced. According to Ochoa et al. [106] and later (yr. 2017) by Davar and Sadri [173], permeability values of bone are between $0.5 \times 10^{-8}$ and $5 \times 10^{-8} \mathrm{~m}^{2}$. In addition, Singh et al. [83] suggests that a permeability above $5 \times 10^{-8} \mathrm{~m}^{2}$ allows for superior bone growth. Evaluating the performance of the UCs (Fig. 9) used as the foundation for the scaffolds, all design show K values above 5 $\mathrm{m}^{2} / 10^{8}$. In addition, $\mathrm{UC} 2$ showed the best performance by delivering a $\mathrm{K}$ value above but closer to the bone being replaced.

Looking at the pressure difference $(\Delta P)$ as shown in Fig. 7, porosity alone is not an indication of the permeability. When the porosity increased from 70.98 to $74.31, \Delta P$ increased. However, on a subsequent increase in porosity, $\Delta P$ decreased (Fig. 9a). The reasons for this is the complexity of the pore structure influencing the fluid flow as can be observed from Fig. 7 and 8 . A concentration of high pressure at opposing surfaces can be seen in Fig. 7 as a result of poor hydrodynamic geometry of UC1, 3 and 4. Overall, UC2 showed the most complex pressure profile driven by the expanding and narrowing pore size at a porosity of $73.31 \%$. Other designs despite different porosities showed similar pressure grading (Fig. 7) reinforcing a higher significance to geometry in comparison to porosity.

Various studies have attempted to quantify the factors that influence the permeability of a scaffold. One of the most prominent studies in this aspect was from O'Brien et al. [174] who proposed that permeability depended primarily on porosity. Later Dias et al. [22] added to it that the individual pore size also has an influence in addition to the volumetric porosity based on computational analysis. While permeability does improve with an increase in $\phi$ and pore size, 
the result of this study signifies the influence of geometry or pore shape which has been disregarded in previous studies.

Similar trends can also be observed for flow velocity (Fig. 8), where UC6 can be seen to have the least effect due to high porosity $(\phi=90.69 \%)$ followed by UC4 $(\phi=80.17 \%)$. While a higher average velocity can be beneficial to transport nutrients and oxygen deeper into the scaffold it can also cause cell washout which slows osteoblast attachment [175]. On the other hand, a significant flow declaration was observed for $\mathrm{UC1}(\phi=68.46 \%)$ followed by UC3 $(\phi=74.05 \%)$ and UC5 $(\phi=81.14 \%)$. The reason for this is the narrow pore size and geometry. According to Van Bael et al. [21], lower velocity and higher surface friction are beneficial as they can increase the chances of osteoblast attachment. Consequently, the flow velocity within the scaffold is an important parameter for both the transport of nutrients and cell attachment. Between the six scaffolds tested UC2 shows a good balance of areas with high and low flow velocities resulting in a closer to bone $\mathrm{K}$ at $74.31 \%$ porosity.

While permeability is significant so is the mechanical performance to maintain the structural integrity and to provide a stable joint. While Ti6Al4V inherently presents high stiffness (E), and strength $\left(\sigma_{y}\right)$, this shields the stress that is being distributed to the adjacent bone tissue and leads to bone resorption commonly referred to as stress shielding [176-180]. Therefore, the mechanical properties of the scaffolds should match or ideally falls slightly below that of the native bone tissue being replaced. The result of the theoretical evaluation following Ashby's criterion (Fig. 10) showed SC1 as having the highest theoretical stiffness $\left(E_{t h r}\right)$ and strength $\left(\sigma_{y(t h r)}\right)$ of $10.42 \mathrm{GPa}$ and $152.30 \mathrm{MPa}$. The lowest stiffness and strength were exhibited by SC6 at $0.91 \mathrm{GPa}\left(E_{t h r}\right)$ and $24.42 \mathrm{MPa}\left(\sigma_{y(t h r)}\right)$ representative of a $\rho_{r}$ of 0.0931 . Comparing the performance of the unit cells with scaffold (Fig. 10) the difference observed was insignificant and is representative of the slight difference in $\rho_{r}$ when the UCs were morphed onto the scaffold geometry. Accordingly, the theoretical stiffness of the scaffolds falls towards the lower spectrum of the cortical bone at 0.91 to $10.41 \mathrm{GPa}$.

The literature $[23,134,136,181,182]$ on AM manufactured metal lattices raises the repeatability of highly porous scaffolds as a major concern that affects both reproducibility and predictability of their mechanical performance. Although FEM could predict the stiffness and strength of porous scaffolds, the accuracy of the prediction reported in most cases is low [183-185]. This has been primarily due to the incomplete melting of the metal powders and the significance of the surface roughness at high porosity. Furthermore, internal pore sizes of scaffolds are often prone to high-stress concentration leading to failure which is often not analysed. Considering these aspects, both FEA and physical tests are conducted in this study and the results compared. The aim was not only to evaluate the accuracy of the FE model as a design tool but also to quantify the variation in mechanical performance between the ideal geometry (CAD) and SLM prototype. 
Furthermore, the FE model was used to quantify the stress concertation that is a significant feature of highly porous scaffolds, especially for scaffolds with a permeability at or above bone.

Analysing the stress-strain curves (Fig. 11), SC1 and SC2 showed similar $\sigma_{u}$ primarily due to only a $2.5 \%$ difference in porosity between the two designs. Despite this SC2 showed comparatively low $\sigma_{y}$ due to the interaction of the deformed material in the pores. For SC3, the performance was found to be typical of a reticulated mesh [126] as shown in Fig. 11c. In comparison, SC4 and SC6 showed total collapse following the first plateau (Fig. 11d and 11f). This often happens when the crack propagation happens within a cellular layer or where the porosity is significantly high. In this case, a combination of these two variables and the collapse of the vertical load transfer beams can be observed (Fig. 13). Behaviour of SC5 was of a stochastic $[129,130]$ (Fig. 11e) nature; stochastic structures are often heterogeneous resulting in a mixture of strong and weak regions. As a result, the mechanical performance is often dominated by the weak regions. According to Zheng et al. [186], drastic degradation in mechanical behaviour in stochastic foams at or above $90 \%$ porosities shows a quadratic (or higher order) scaling relationship between elasticity and density as well as strength and density. Consequently, the mechanical properties of this type of structures can be attained by unit cells arranged in a hierarchical order as demonstrated by SC5.

Overall as listed in Table 6, the stiffness of the scaffold designs tested was within 2.21 to 10.9 GPa with SC6 and SC4 showing the lowest and highest performance. The trend was similar for both the yield and ultimate strength at a range of 39.49-236.34 and 44.99-284.49 $\mathrm{MPa}$ respectively. When compared to the performance of the bone being replaced, the closest performance was exhibited by SC4 with the stiffness being lower and both $\sigma_{y}$ and $\sigma_{c}$ being higher. Even though the performance of SC4 appears to be an exception, it is an otherwise expected behaviour due to the relationship between $\rho_{r}, \sigma_{y}$ and $\mathrm{E}$ facilitated by a low $K_{t}$. For other designs, the significance of $\sigma_{y}$ on the mechanical performance is drastically reduced by high $K_{t}$. A combination of low stiffness and high strength ensures low stress shielding and maladapted stress concentration while reducing the chances for catastrophic failure.

Table 6. Performance summary of the scaffold designs with respect to host bone.

\begin{tabular}{|c|c|c|c|c|c|c|c|}
\hline \multirow{2}{*}{ Performance } & \multicolumn{6}{|c|}{ Scaffold Designs } & \multirow{2}{*}{ Bone } \\
\hline & $\mathrm{SC} 1$ & $\mathrm{SC} 2$ & $\mathrm{SC} 3$ & $\mathrm{SC} 4$ & SC5 & SC6 & \\
\hline $\mathrm{E}(\mathrm{GPa})$ & 6.81 & 5.14 & 2.58 & 10.9 & 3.69 & 2.21 & 18.01 \\
\hline$\sigma_{y}(\mathrm{MPa})$ & 125.86 & 79.45 & 67.07 & 236.34 & 58.95 & 39.49 & 126.41 \\
\hline$\sigma_{u}(\mathrm{MPa})$ & 198.52 & 194.95 & 77.41 & 284.49 & 69.09 & 44.99 & 140.00 \\
\hline$K\left(\mathrm{~m}^{2}\right)$ & $1.80 \mathrm{e}-7$ & $6.81 \mathrm{e}-8$ & $1.23 \mathrm{e}-7$ & $1.26 \mathrm{e}-7$ & $1.63 \mathrm{e}-7$ & $1.75 \mathrm{e}-7$ & $5.0 \mathrm{e}-8$ \\
\hline$K_{t}$ & 5.73 & 12.18 & 35.21 & 5.07 & 39.02 & 40.34 & $4.17-5.36[187]$ \\
\hline
\end{tabular}


According to Patel et al. [188], numerical simulation using the Finite Element Method (FEM) is an appealing methodology to predict the mechanical performance of scaffolds and can subsequently identify optimum design for customised bone replacements. Researchers $[157,183,189,190]$ have been broadly applying FEM to porous scaffold designs with arbitrary macroscopic porous models in an attempt to limit the computational complexity. Where there has been evidence of microscopic modelling [191,192], they have been limited unit cells or single lattices at the linear-elastic level.

While linear-elastic models have been shown to be effective for highly stiff and brittle scaffolds such as bio-ceramics due to their low strain to failure $(<0.003)$, the accuracy is significantly affected for materials featuring low stiffness and high strain rate. Furthermore, in addition to E, the onset of failure represented by $\sigma_{y}$ is an important parameter when designing stiffnesscontrolled scaffolds. Therefore, this study utilises the Bilinear Isotropic Strain Hardening (BISO) model to predict both $\mathrm{E}$ and $\sigma_{y}$ at a reasonable computational cost. Recent studies by Patel $e t$ al. [188] experimented with BISO and showed to be effective while modelling porous scaffolds experiencing compression. Different from the physical test, the accuracy of the post-failure deformation is insignificant in scaffold designs as the scaffolds are expected not to fail once implanted.

Comparing the FE predictions with experimental test data as shown in Fig. 12, reasonable agreement can be observed for both $\mathrm{E}$ (Fig. 12a) and $\sigma_{y}$ (Fig. 12b). For effective elastic modulus, FEA overestimated the performance with the lowest and highest difference exhibited at $3.46 \%$ (SC1) and 19.58\% (SC3), respectively. When it comes to the yield strength, the best and worst agreement were found to be at $7.21 \%$ (SC2) and $24.72 \%$ (SC5), respectively. Numerical overestimation of scaffold performance can be partly attributed to the presence of imperfect surface topology that has not been accounted for in the FE model. The influence of the SLM process in this regard is significant due to the stair-step effect which has been well documented by Chen et al. [193] in Ti6Al4V. In addition, Cahill et al. [194] and Doyle et al. [195] found that the porous architecture of the scaffold causes significant variation from ideal geometry which often impact on calculations underpinned by CAD data.

The prediction capability of finite element numerical models also depends on the range of compressive strain experienced by the structure [189]. For a homogenous simple cubic strand featuring a length to height ratio of 1 , it has been reported that macroscopic numerical models tend to underestimate the absolute values of compressive stress at strains less than $30 \%$. In comparison, the inter-layer overlap facilitated by SLM usually contributes to higher experimental stresses being developed within the structure. On the other hand, numerical models tend to overestimate stress at high strains due to buckling effects. A similar observation was reported by Duoss et al. [196] when working with AM lattice structures. 
Overall, the literature on numerical studies of porous metal scaffolds [185,197-201] reports differences in result between physical tests of up to $200 \%$ (2 folds) $[16,18,185]$ for AM porous metal samples. A difference of up to $30 \%$ is generally accepted as the best case achievable for highly porous SLM scaffolds modelled at a macroscopic scale $[143,144]$. In comparison the numerical models developed in this study show differences in the range of 3.46 to $24.72 \%$; an acceptable case for highly porous lattices demonstrating good agreement. Consequently, the validated numerical model was used to study the stress concentration induced.

In addition to the stiffness and strength, studying the post-yield behaviour of the scaffolds (Fig. 11) is critical to identify further refinement in both design and SLM process parameters. While the geometric freedom facilitated by SLM allows the manufacturing of otherwise challenging and complex geometries. The failure modes (Fig. 13) often characterised by the post-yield behaviour allows assessing the reproducibility and structural integrity of the scaffold. This is particularly crucial as SLM is known to be affected by local instabilities in the melt pool [202]. At high energy densities, the melt pool can become unstable as a result of the rapid thermo-capillary convective motion often referred to as Marangoni flow [203-205]. Such instabilities results in balling causing significant dimensional deviation in comparison to the idealised CAD geometry. Furthermore, Rayleigh instability $[206,207]$ can occur in the case of low energy density melt pools.

According to Ciurana et al. [208], the ideal scenario is when smooth regular scan tracks are formed without any irregularities despite the geometry or porosity. To a certain extent the deviation in $\sigma_{y}$ between the numerical and physical results can aid in understanding the extend of instabilities during the manufacturing process. Taking the case of the scaffold (SC6) that features the highest porosity, FEA underestimated $\sigma_{y}$ by $18.38 \%$ (Fig. 12b) and the failure was observed due to localised buckling of the vertical beam (Fig. 13f). It can be seen that the failure is typical of highly porous cellular structures featuring thin beams and it not representative of any manufacturing instabilities. For SC5 even though a difference of $24.72 \%$ (Fig. 12b) was observed, the physical test results where higher; in addition, the failure mode (Fig. 13e) shows repetitive minor crush bands, a classical behaviour of stochastic structure [209].

On the contrary, the failure of SC4 was overestimated $10.59 \%$ by FEA (Fig. 12b) which represents a possibility of process (SLM) induced irregularity. Furthermore, the failure was abrupt with a sudden reduction in the load-carrying capacity. The deformation mode (Fig. 13d) can be further attributed to the highly stiff axial and lateral meshes as a result of the perfectly matched layers of the repeating UC. This can be further correlated to the observations by Mower and Long [210] where horizontally manufactured Ti6Al4V specimens showed higher $\sigma_{y}$ but lower failure strain.

Even though SC1, SC2 and SC3 exhibited a similar trend in the post-yield behaviour, FEA underestimated the strength of SC1 and SC3 by 11.94 and $12.60 \%$, respectively. However, the 
numerical prediction overestimated $\sigma_{y}$ for SC2 by $7.21 \%$. As shown in Fig. 13a-c, SC1 and SC3 feature relatively large and uniform pore sizes failing through the formation of crush bands. The fracture initiation for these two designs are also observed along the same region and propagates through the structure showing that no manufacturing instability inclusions have been caused due to the SLM. In general, for scaffolds SC1 and SC3, the failure pattern resembles a case where multiple pore sizes are arranged regularly [202].

The failure of SC2 can be attributed to highly localised failure as shown in Fig. 13b, despite the highly dense pore architecture. The failed sample shows limited layer interaction and the failure was primarily concentrated along a single band (upper quarter). This, when coupled with the decreasing pore size facilitated by the shape of the UC is the reason for the two distinctive slopes on the run-up to the ultimate stress (Fig. 11b). The failure pattern resembling thin wall buckling initiated by SLM induced inclusion defect explains why the FEA model overestimated the failure. Despite this, a $7.21 \%$ discrepancy between the numerical and experimental results shows that the numerical model is suitable to predict the performance of these highly porous scaffolds. Overall, both the numerical and experimental results show that the shape of the unit cells bears a higher significance on the scaffold deformation due to its influence of the SLM process compared to the volumetric porosity. This is because the porous architecture of the scaffolds results in pores of different shapes and sizes. When the scaffold is loaded, the walls of the pores experiences stress due to the change in geometry. Accurate evaluation of this stress concentration effect is significant to effective design as it drastically reduces the overall strength of the scaffolds. The effect of such stress concentrations on the performance of cellular materials is usually quantified using the stress concentration factor $\left(K_{t}\right)$ [211-213].

While the influence of $K_{t}$ on the mechanical performance under quasi-static mechanical properties is the primary consideration for this study, its influence on fatigue behaviour is also critical for the proper functioning of metallic scaffolds [214-217]. Even though much of what is discussed regarding the influence of $K_{t}$ is valid regardless of the nature of loading, fatigue performance stills remain a concern for AM biomaterials [218]. When scaffolds feature geometrical changes that give rise to high stress concentrations, fatigue failures generally tend to initiate from these locations [219-221]. Therefore, considering the bone scaffolds are subjected to both static and cyclical loading, the best approach is to conceive pore shapes that can have the lowest possible $K_{t}$.

Evaluating the location of the maximum stress field as shown in Fig. 14, $\sigma_{\max }$ for SC3, SC5 and SC6 showed a significant spread along the outer surface and the intersections of the beams. The von Mises stress along the highest sections was significantly larger than in the median part of the beams, which explains the crack initiation and plastic behaviour of these scaffolds shown in Fig. 13 and 11 respectively. Out of all the scaffolds studied, SC1 and SC4 exhibited stress concentrations only along the change in geometry facilitated by the respective UCs. This meant 
that the for these designs potential location of stress concentration is predictable allowing to incorporate traditional strategies like fillets for abatement or reduction of the stress concentration.

The plastic failure of these scaffolds (Fig. 11) also shows significant engagement from adjacent cells demonstrating the limited influence of stress concentration. Similar observations were made by Lohmuller et al. [212] when studying the mechanical strength of cubic lattice architecture. Despite the complex shape, the curved structure of SC2 was also found to be beneficial in reducing stress concentration in comparison to SC3, SC5 and SC6. However, this structure did exhibit stress concentration on the surface (Fig. 14b) of the scaffold primarily due to the discrepancy in geometry caused when UC2 was morphed to the cylindrical profile.

In general, the mechanical performance of the scaffolds was found to be significantly affected by the magnitude of $\sigma_{\max }$ as shown in Fig. 15. While this can be primarily attributed to the shape of the pores the overall shape of the scaffolds also influenced certain designs (SC2). The drop in E (Fig. 15a) and $\sigma_{y}$ (Fig. 15b) was found to be proportional to the increase in stress concentration $\left(\sigma_{\max }\right)$. While, the effect of $\sigma_{\max }$ on $\sigma_{y}$ is a well-established phenomenon, the relationship to stiffness is more representative of porous metals [222]. From a structural mechanics perspective, the pore shapes within the structure can be considered a discontinuity such as a hole, high localised stress occurs near the discontinuity. For a perfectly circular discontinuity the resulting $\sigma_{\max }$ can be expected to be a little over three times the nominal stress. Further variation in the discontinuity increases the $\sigma_{\max }$ significantly as demonstrated in this study.

Compounding the effect of stress concentration can be the surface roughness exhibited by the SLM manufactured parts, which can be the reason for FEA overestimating the performance of certain scaffolds. According to Atif et al. [223], the impact of stress concentration is adverse in brittle material in comparison to ductile material. Plastic deformation in a ductile material occurs when the $\sigma_{y}$ of the bulk material is exceeded by $\sigma_{\max }$. Further compressive load results in an increase in localised strain where stress concentration is being experienced. The resulting strain hardening increases the stress adjacent to the locations of initial stress concentration.

The strain hardening effect is largely due to the creation of crystal defects, primarily dislocations, during plastic deformation. The hardening can reach saturation once the defect creation and annihilation rates balance. Porous structures inevitably contain features that cause the stress to concentrate and hence initiate plastic deformation. The resulting strain hardening of the deforming region locally increases the yield strength in that region [224-226]. However, the material continues to fail as the strain hardening cannot raise the yield strength at a rate greater than the increase in stress due to the reduced area of the deformation. Consequently, the reduced area of the failed beams further increases the stress. This effect in certain cases can also be compounded by the hard and soft interface resulting from strain hardening [227]. However, if 
the material exhibits ductile behaviour, the associated distribution of stress tends to be more uniform. This means that a ductile material under quasi-static compression is unlikely to develop the full numerical $K_{t}$.

In comparison, the extent of stress redistribution in brittle materials is significantly less [228]. This means that a $K_{t}$ close to numerical value can often be experienced by brittle material. Based on Griffith crack theory [229], depending upon the geometry, pore shapes will drastically lower the mechanical properties of brittle structures. Studies by Gorsse et al. [230] have shown that irrespective of the build direction, AM Ti6Al4V structures exhibits a mixture of brittle and ductile modes of failure. The observations were further reinforced by the studies of Krakhmalev et al. [231], Simonelli et al. [232,233] and Zaefferer et al. [234] on laser melted Ti6Al4V. Similarly, the failure behaviour observed for the scaffolds can be classified as brittle especially at high porosities. Furthermore, the scaffold SC3, SC5 and SC6 feature narrow beams resulting in high $K_{t}$ (Fig. 16), which reduces the mechanical properties (Fig. 15). Combining this with the brittle nature of failure means that designs with controlled $K_{t}$ are crucial in achieving targeted stiffness and strength for highly porous laser melted Ti6Al4V scaffolds.

While significant attempts $[21,235,236]$ have been made to characterise different functional parameters of scaffolds in insolation, there is still a significant gap between the influence of each parameter on the performance of scaffold as a whole [237]. Accordingly, this study takes a more holistic approach to develop fully porous AM scaffolds targeting at permeability, stiffness and strength at the same time assessing the influence of stress concentration paying attention to both porosity and pore-geometry. A higher than bone permeability has been shown to prevent scaffold occlusion, which in turn promotes tissue growth [238]. Consequently, all bone scaffolds were designed to feature a permeability in the range but slightly higher than that of the host bone. Based on the results of effective elastic modulus (stiffness), compressive strength (yield strength), permeability $(\mathrm{K})$ and stress concentration factor $\left(K_{t}\right)$, the scaffold architecture that most effectively mimic the host bone was identified as SC4. This study validates the use of SLM in manufacturing Ti6Al4V bone scaffolds that can promote bone tissue generation at the same timing lowering maladapted stress concentration and stress shielding.

\subsection{Future work}

Quasi-static mechanical performance of AM porous scaffolds is increasingly being documented, however, in most cases, key criteria such as permeability and stress concentration are omitted. Furthermore, numerical and experimental evaluation of the dynamic behaviour of these scaffolds

under life-like loading conditions is rare. Consequently, continued study will look at simulating dynamic loading while incorporating a global anatomical bone profile to derive functional bone scaffolds. This will be carried out while paying careful attention to permeability, stiffness, strength and stress concentration with a view to further reducing the effects of maladapted stress 
concentration and stress shielding. In addition, studying both quasi-static and fatigue of AM auxetic and surface/sheet/plate bone scaffolds to support the design of implants with enhanced functionalities will be considered.

\section{Conclusion}

A closer to bone permeability improves osteoblasts attachment and significantly enhances the biological compatibility of bone scaffolds. Accordingly, this study investigated fully porous laser melted Ti6Al4V bone scaffolds considering, permeability $(\mathrm{K})$, stiffness $(\mathrm{E})$, strength $\left(\sigma_{y}\right)$ and stress concentration factor $\left(K_{t}\right)$. The results revealed that the accuracy of Ashby's criterion is limited when it comes to predicting the performance of scaffolds featuring complex pore geometries. On the other hand, the FE Bilinear Isotropic Strain Hardening (BISO) material model was found to be effective to predict the performance of SLM scaffolds within an accuracy of $3.46-24.72 \%$. The laser melted Ti6Al4V scaffolds featuring porosities of 68.46 to $90.98 \%$ exhibited permeability, stiffness, compressive strength and stress concentration factor of 6.81$18.0 \mathrm{~m}^{2} / 10^{8}, 2.21-10.90 \mathrm{GPa}, 39.49-236.34 \mathrm{MPa}$ and $5.07-40.34$ respectively. A performance compatible to the host bone with permeability, stiffness and strength of $5 \mathrm{~m}^{2} / 10^{8}, 18.01 \mathrm{GPa}$ and $140 \mathrm{MPa}$ respectively. The analysis of maximum stress $\left(\sigma_{\max }\right)$ demonstrated bimodal distribution along a relative density $\left(\rho_{r}\right)$ of $0.09-0.31$ exhibiting its primarily dependence to pore shape as opposed to $\rho_{r}$. In addition, both $\mathrm{E}$ and $\sigma_{y}$ was found to be inversely proportional to the magnitude of stress concentration observed. This signifies that $K_{t}$ is an important factor in scaffold design and by controlling it, required stiffness and strength can be achieved irrespective of the targeted porosity. When evaluating the failure modes, the scaffolds generally demonstrated a brittle failure which also shows the importance of controlling stress concentration. Out of the six scaffolds, the best performance was observed for SC4 with an effective elastic modulus of $10.9 \mathrm{GPa}$, a compressive strength of $236.34 \mathrm{MPa}$, permeability of $12.6 \mathrm{~m}^{2} / 10^{8}$ and a stress concentration factor of 5.07. Critical analysis of the stress-strain curve showed that the shape and distribution of the pores can result in both reticulated and stochastic behaviour of the scaffolds, which in turn affects the mechanical performance. Low stiffness, high strength and closer to bone permeability can significantly reduce both stress shielding and maladapted stress concentration while improving osseointegration and bone ingrowth. Consequently, this work demonstrates a methodology to develop functional porous bone scaffolds paying close attention to porosity, pore shape, stress concentration, and permeability. The parameters used in this study can be systematically considered to develop optimum scaffold designs that can be additively manufactured at a targeted porosity of $68.46-90.69 \%$.

\section{References}

[1] A.P. Moreno Madrid, S.M. Vrech, M.A. Sanchez, A.P. Rodriguez, Advances in additive manufacturing for bone tissue engineering scaffolds, Mater. Sci. Eng. C. 100 (2019) 631-644. doi:10.1016/J.MSEC.2019.03.037.

[2] V. Mouriño, A.R. Boccaccini, Bone tissue engineering therapeutics: controlled drug delivery in three-dimensional 
scaffolds, J. R. Soc. Interface. 7 (2010) 209-227. doi:10.1098/rsif.2009.0379.

[3] Y. Chen, J.E. Frith, A. Dehghan-Manshadi, H. Attar, D. Kent, N.D.M. Soro, M.J. Bermingham, M.S. Dargusch, Mechanical properties and biocompatibility of porous titanium scaffolds for bone tissue engineering, J. Mech. Behav. Biomed. Mater. 75 (2017) 169-174. doi:10.1016/j.jmbbm.2017.07.015.

[4] L. Tan, M. Gong, F. Zheng, B. Zhang, K. Yang, Study on compression behavior of porous magnesium used as bone tissue engineering scaffolds, Biomed. Mater. 4 (2009) 015016. doi:10.1088/1748-6041/4/1/015016.

[5] D.J. Cohen, A. Cheng, K. Sahingur, R.M. Clohessy, L.B. Hopkins, B.D. Boyan, Z. Schwartz, Performance of laser sintered $\mathrm{Ti}-6 \mathrm{Al}-4 \mathrm{~V}$ implants with bone-inspired porosity and micro/nanoscale surface roughness in the rabbit femur, Biomed. Mater. 12 (2017) 025021. doi:10.1088/1748-605X/aa6810.

[6] Y. Zhu, R. Zhu, J. Ma, Z. Weng, Y. Wang, X. Shi, Y. Li, X. Yan, Z. Dong, J. Xu, C. Tang, L. Jin, In vitro cell proliferation evaluation of porous nano-zirconia scaffolds with different porosity for bone tissue engineering, Biomed. Mater. 10 (2015) 055009. doi:10.1088/1748-6041/10/5/055009.

[7] K.C.R. Kolan, M.C. Leu, G.E. Hilmas, R.F. Brown, M. Velez, Fabrication of 13-93 bioactive glass scaffolds for bone tissue engineering using indirect selective laser sintering, Biofabrication. 3 (2011) 025004. doi:10.1088/1758$5082 / 3 / 2 / 025004$

[8] R.U. Khan, L. Wang, H. Yu, Zain-ul-Abdin, M. Akram, J. Wu, M. Haroon, R.S. Ullah, Z. Deng, X. Xia, Recent progress in the synthesis of poly(organo)phosphazenes and their applications in tissue engineering and drug delivery, Russ. Chem. Rev. 87 (2018) 109-150. doi:10.1070/RCR4757.

[9] S. Miar, A. Shafiee, T. Guda, R. Narayan, Additive Manufacturing for Tissue Engineering, in: 3D Print. Biofabrication, Springer International Publishing, Cham, 2018: pp. 1-52. doi:10.1007/978-3-319-40498-1_2-1.

[10] S.L. Sing, Concepts of Selective Laser Melting for Orthopaedic Implants, in: Springer, Singapore, 2019: pp. 9-36. doi:10.1007/978-981-13-2724-7_2.

[11] E. Provaggi, D.M. Kalaskar, 3D printing families, 3D Print. Med. (2017) 21-42. doi:10.1016/b978-0-08-100717-4.00003-x.

[12] G. Turnbull, J. Clarke, F. Picard, P. Riches, L. Jia, F. Han, B. Li, W. Shu, 3D bioactive composite scaffolds for bone tissue engineering, Bioact. Mater. 3 (2018) 278-314. doi:10.1016/j.bioactmat.2017.10.001.

[13] A. Arjunan, Acoustic absorption of passive destructive interference cavities, Mater. Today Commun. 19 (2019) 68-75. doi:10.1016/j.mtcomm.2018.12.012.

[14] A. Arjunan, Targeted sound attenuation capacity of 3D printed noise cancelling waveguides, Appl. Acoust. 151 (2019) 30-44. doi:10.1016/J.APACOUST.2019.03.008.

[15] S.M. Ahmadi, G. Campoli, S. Amin Yavari, B. Sajadi, R. Wauthle, J. Schrooten, H. Weinans, A.A. Zadpoor, Mechanical behavior of regular open-cell porous biomaterials made of diamond lattice unit cells, J. Mech. Behav. Biomed. Mater. 34 (2014) 106-115. doi:10.1016/j.jmbbm.2014.02.003.

[16] K. Bari, A. Arjunan, Extra low interstitial titanium based fully porous morphological bone scaffolds manufactured using selective laser melting, J. Mech. Behav. Biomed. Mater. 95 (2019) 1-12. doi:10.1016/j.jmbbm.2019.03.025.

[17] A. Vance, K. Bari, A. Arjunan, Compressive performance of an arbitrary stiffness matched anatomical Ti64 implant manufactured using Direct Metal Laser Sintering, Mater. Des. 160 (2018) 1281-1294. doi:10.1016/j.matdes.2018.11.005.

[18] A. Vance, K. Bari, A. Arjunan, Investigation of Ti64 sheathed cellular anatomical structure as a tibia implant, Biomed. Phys. Eng. Express. 5 (2019) 035008. doi:10.1088/2057-1976/ab0bd7.

[19] M.A. Surmeneva, R.A. Surmenev, E.A. Chudinova, A. Koptioug, M.S. Tkachev, S.N. Gorodzha, L.-E. Rännar, Fabrication of multiple-layered gradient cellular metal scaffold via electron beam melting for segmental bone reconstruction, Mater. Des. 133 (2017) 195-204. doi:10.1016/J.MATDES.2017.07.059.

[20] Khoon S. Lim; Marissa Baptista; Shahana Moon; Tim B.F. Woodfield; Jelena Rnjak-Kovacina, Microchannels in Development, Survival, and Vascularisation of Tissue Analogues for Regenerative Medicine, Trends Biotechnol. (2019). doi:doi.org/10.1016/j.tibtech.2019.04.004.

[21] S. Van Bael, Y.C. Chai, S. Truscello, M. Moesen, G. Kerckhofs, H. Van Oosterwyck, J.-P. Kruth, J. Schrooten, The effect of pore geometry on the in vitro biological behavior of human periosteum-derived cells seeded on selective lasermelted Ti6Al4V bone scaffolds, Acta Biomater. 8 (2012) 2824-2834. doi:10.1016/j.actbio.2012.04.001. 
[22] M.R. Dias, P.R. Fernandes, J.M. Guedes, S.J. Hollister, Permeability analysis of scaffolds for bone tissue engineering, J. Biomech. 45 (2012) 938-944. doi:10.1016/j.jbiomech.2012.01.019.

[23] S. Ma, Q. Tang, Q. Feng, J. Song, X. Han, F. Guo, Mechanical behaviours and mass transport properties of bonemimicking scaffolds consisted of gyroid structures manufactured using selective laser melting, J. Mech. Behav. Biomed. Mater. 93 (2019) 158-169. https://www.sciencedirect.com/science/article/pii/S175161611831258X?via\%3Dihub (accessed May 10, 2019).

[24] Q. Ran, W. Yang, Y. Hu, X. Shen, Y. Yu, Y. Xiang, K. Cai, Osteogenesis of 3D printed porous Ti6Al4V implants with different pore sizes, J. Mech. Behav. Biomed. Mater. 84 (2018) 1-11. doi:10.1016/j.jmbbm.2018.04.010.

[25] N. Taniguchi, S. Fujibayashi, M. Takemoto, K. Sasaki, B. Otsuki, T. Nakamura, T. Matsushita, T. Kokubo, S. Matsuda, Effect of pore size on bone ingrowth into porous titanium implants fabricated by additive manufacturing: An in vivo experiment, Mater. Sci. Eng. C. 59 (2016) 690-701. doi:10.1016/j.msec.2015.10.069.

[26] S.I. Roohani-Esfahani, P. Newman, H. Zreiqat, Design and Fabrication of 3D printed Scaffolds with a Mechanical Strength Comparable to Cortical Bone to Repair Large Bone Defects, Sci. Rep. 6 (2016) 19468. doi:10.1038/srep19468.

[27] K. Zhang, Y. Fan, N. Dunne, X. Li, Effect of microporosity on scaffolds for bone tissue engineering, Regen. Biomater. 5 (2018) 15-124. doi:10.1093/rb/rby001.

[28] W. Zhang, X. Frank Walboomers, T.H. van Kuppevelt, W.F. Daamen, Z. Bian, J.A. Jansen, The performance of human dental pulp stem cells on different three-dimensional scaffold materials, Biomaterials. 33 (2006) 5658-68. doi:10.1016/j.biomaterials.2006.07.013.

[29] K. Alvarez, H. Nakajima, Metallic scaffolds for bone regeneration, Materials (Basel). 2 (2009) 790-832. doi: $10.3390 / \operatorname{ma} 2030790$.

[30] T. Albrektsson, C. Johansson, Osteoinduction, osteoconduction and Osseointegration, J. Eur. Spine. 10 (2001) 96-101.

[31] L.F. Bonewald, Chapter 10 - Osteocyte Biology, in: Osteoporosis, 2013. doi:10.1016/B978-0-12-415853-5.00010-8.

[32] T. Wu, S. Yu, D. Chen, Y. Wang, Bionic Design, Materials and Performance of Bone Tissue Scaffolds, Materials (Basel). 10 (2017) 1187. doi:10.3390/ma10101187.

[33] L. Berzina-Cimdina, M. Prakasam, J. Locs, A. Largeteau, D. Loca, K. Salma-Ancane, Biodegradable Materials and Metallic Implants-A Review, J. Funct. Biomater. 8 (2017) 44. doi:10.3390/jfb8040044.

[34] K. Su, H. Wang, C. Wang, P. Liang, L. Su, P. Ji, The effect of 3D-printed Ti6Al4V scaffolds with various macropore structures on osteointegration and osteogenesis: A biomechanical evaluation, J. Mech. Behav. Biomed. Mater. 88 (2018) 488-496. doi:10.1016/j.jmbbm.2018.08.049.

[35] A. Ataee, Y. Li, D. Fraser, G. Song, C. Wen, Anisotropic Ti-6Al-4V gyroid scaffolds manufactured by electron beam melting (EBM) for bone implant applications, Mater. Des. 137 (2018) 345-354. doi:10.1016/j.matdes.2017.10.040.

[36] M. Whittaker, Titanium Alloys, Metals (Basel). 5 (2018) 1437-1439. doi:10.3390/met5031437.

[37] S. Liu, Y.C. Shin, Additive manufacturing of Ti6Al4V alloy: A review, Mater. Des. 164 (2019) 107552. doi:10.1016/J.MATDES.2018.107552.

[38] C.Y. Lin, N. Kikuchi, S.J. Hollister, A novel method for biomaterial scaffold internal architecture design to match bone elastic properties with desired porosity, J. Biomech. 37 (2004) 623-636. doi:10.1016/j.jbiomech.2003.09.029.

[39] T. Kokubo, H.M. Kim, M. Kawashita, Novel bioactive materials with different mechanical properties, Biomaterials. (2003). doi:10.1016/S0142-9612(03)00044-9.

[40] M. Amaral, M.A. Lopes, R.F. Silva, J.D. Santos, Densification route and mechanical properties of Si3N4-bioglass biocomposites, Biomaterials. 23 (2002) 857-862. doi:10.1016/S0142-9612(01)00194-6.

[41] D.W. Hutmacher, J.T. Schantz, C.X.F. Lam, K.C. Tan, T.C. Lim, State of the art and future directions of scaffold-based bone engineering from a biomaterials perspective, J. Tissue Eng. Regen. Med. 1 (2007) 245-260. doi:10.1002/term.24.

[42] L. Zhao, X. Pei, L. Jiang, C. Hu, J. Sun, F. Xing, C. Zhou, Y. Fan, X. Zhang, Bionic design and 3D printing of porous titanium alloy scaffolds for bone tissue repair, Compos. Part B Eng. 162 (2019) 154-161.

doi:10.1016/j.compositesb.2018.10.094.

[43] Ó.L. Rodríguez-Montaño, C.J. Cortés-Rodríguez, A.E. Uva, M. Fiorentino, M. Gattullo, G. Monno, A. Boccaccio, Comparison of the mechanobiological performance of bone tissue scaffolds based on different unit cell geometries, J. 
Mech. Behav. Biomed. Mater. 83 (2018) 28-45. doi:10.1016/j.jmbbm.2018.04.008.

[44] L. Yan, J. Wu, L. Zhang, X. Liu, K. Zhou, B. Su, Pore structures and mechanical properties of porous titanium scaffolds by bidirectional freeze casting, Mater. Sci. Eng. C. 75 (2017) 335-340. doi:10.1016/j.msec.2016.12.044.

[45] S. Gómez, M.D. Vlad, J. López, E. Fernández, Design and properties of 3D scaffolds for bone tissue engineering, Acta Biomater. 42 (2016) 341-350. doi:10.1016/j.actbio.2016.06.032.

[46] S. Ghouse, N. Reznikov, O.R. Boughton, S. Babu, K.C.G. Ng, G. Blunn, J.P. Cobb, M.M. Stevens, J.R.T. Jeffers, The design and in vivo testing of a locally stiffness-matched porous scaffold, Appl. Mater. Today. 15 (2019) 377-388. doi:10.1016/j.apmt.2019.02.017.

[47] C. Greiner, S.M. Oppenheimer, D.C. Dunand, High strength, low stiffness, porous NiTi with superelastic properties, Acta Biomater. 1 (2005) 705-716. doi:10.1016/j.actbio.2005.07.005.

[48] L.D. Bobbio, S. Qin, A. Dunbar, P. Michaleris, A.M. Beese, Characterization of the strength of support structures used in powder bed fusion additive manufacturing of Ti-6Al-4V, Addit. Manuf. 14 (2017) 60-68. doi:10.1016/J.ADDMA.2017.01.002.

[49] P. Mercelis, J. Kruth, Residual stresses in selective laser sintering and selective laser melting, Rapid Prototyp. J. 12 (2006) 254-265. doi:10.1108/13552540610707013.

[50] J. Brezinová, D. Draganovská, G. Ižaríková, J. Živčák, A. Guzanová, R. Hudák, Influence of Build Orientation, Heat Treatment, and Laser Power on the Hardness of Ti6Al4V Manufactured Using the DMLS Process, Metals (Basel). 7 (2017) 318. doi:10.3390/met7080318.

[51] E. Salsi, M. Chiumenti, M. Cervera, Modeling of Microstructure Evolution of Ti6Al4V for Additive Manufacturing, Metals (Basel). 8 (2018) 633. doi:10.3390/met8080633.

[52] F.X. Gil Mur, D. Rodríguez, J.A. Planell, Influence of tempering temperature and time on the $\alpha^{\prime}-\mathrm{Ti}-6 \mathrm{~A} 1-4 \mathrm{~V}$ martensite, J. Alloys Compd. 234 (1996) 287-289. doi:10.1016/0925-8388(95)02057-8.

[53] X.P. Li, J. Van Humbeeck, J.P. Kruth, Selective laser melting of weak-textured commercially pure titanium with high strength and ductility: A study from laser power perspective, Mater. Des. 116 (2017) 352-358. doi:10.1016/j.matdes.2016.12.019.

[54] R. Krishna Alla, K. Ginjupalli, N. Upadhya, M. Shammas, R. Krishna Ravi, R. Sekhar, Surface roughness of implants: A review, Trends Biomater. Artif. Organs. 25 (2011) 112-118. doi:10.1007/s11056-007-9051-x.

[55] M. Todea, A. Vulpoi, C. Popa, P. Berce, S. Simon, Effect of different surface treatments on bioactivity of porous titanium implants, J. Mater. Sci. Technol. 35 (2019) 418-426. doi:10.1016/j.jmst.2018.10.004.

[56] A. Entezari, Z. Zhang, A. Sue, G. Sun, X. Huo, C.C. Chang, S. Zhou, M. V. Swain, Q. Li, Nondestructive characterization of bone tissue scaffolds for clinical scenarios, J. Mech. Behav. Biomed. Mater. 89 (2019) $150-161$. doi:10.1016/j.jmbbm.2018.08.034.

[57] S. Karuppudaiyan, K. Singh, V. Santosh, Finite element analysis of scaffold for large defect in femur bone, ICAME. 402 (2018) IOP Conference Series: Materials Science and Engin. https://iopscience.iop.org/article/10.1088/1757$899 \mathrm{X} / 402 / 1 / 012096$.

[58] E. Gallegos-Nieto, H.I. Medellín-Castillo, D.F. de Lange, A complete structural performance analysis and modelling of hydroxyapatite scaffolds with variable porosity, Comput. Methods Biomech. Biomed. Engin. 18 (2015) 1225-1237. doi:10.1080/10255842.2014.889690.

[59] J. Kadkhodapour, H. Montazerian, S. Raeisi, Investigating internal architecture effect in plastic deformation and failure for TPMS-based scaffolds using simulation methods and experimental procedure, Mater. Sci. Eng. C. 43 (2014) 587-97. https://www.ncbi.nlm.nih.gov/pubmed/25175253.

[60] J. Parthasarathy, B. Starly, S. Raman, A design for the additive manufacture of functionally graded porous structures with tailored mechanical properties for biomedical applications, J. Manuf. Process. 13 (2011) 160-170. doi:10.1016/j.jmapro.2011.01.004.

[61] D. Ali, S. Sadri, Computational Fluid Dynamics Study of the Effects of Surface Roughness on Permeability and Fluid Flow-Induced Wall Shear Stress in Scaffolds, 46 (2018) 2023-2035. https://link.springer.com/article/10.1007/s10439-0182101-Z.

[62] R. Lakes, Materials with structural hierarchy, Nature. 361 (1993) 511-515. doi:10.1038/361511a0. 
[63] A. Baroutaji, A. Arjunan, A. Niknejad, T. Tran, A.-G. Olabi, Application of Cellular Material in Crashworthiness Applications: An Overview, in: Ref. Modul. Mater. Sci. Mater. Eng., Elsevier, 2019. doi:10.1016/B978-0-12-8035818.09268-7.

[64] M.F. Ashby, The properties of foams and lattices, Philos. Trans. R. Soc. A Math. Phys. Eng. Sci. 364 (2006) 15-30. doi:10.1098/rsta.2005.1678.

[65] J. Bauer, S. Hengsbach, I. Tesari, R. Schwaiger, O. Kraft, High-strength cellular ceramic composites with 3D microarchitecture, Proc. Natl. Acad. Sci. U. S. A. 111 (2014) 2453-2458. doi:10.1073/pnas.1315147111.

[66] S. Yang, K.-F. Leong, Z. Du, C.-K. Chua, The design of scaffolds for use in tissue engineering. Part II. Rapid prototyping techniques, Tissue Eng. 8 (2002) 1-11. doi:10.1089/107632702753503009.

[67] N.K. Tolochko, V.V. Savich, T. Laoui, L. Froyen, G. Onofrio, E. Signorelli, V.I. Titov, Dental root implants produced by the combined selective laser sintering/melting of titanium powders, Proc. Inst. Mech. Eng. Part L J. Mater. Des. Appl. 216 (2002) 267-270. doi:10.1243/146442002760387952.

[68] A. Barbas, A.-S. Bonnet, P. Lipinski, R. Pesci, G. Dubois, Development and mechanical characterization of porous titanium bone substitutes, J. Mech. Behav. Biomed. Mater. 9 (2012) 34-44. doi:10.1016/j.jmbbm.2012.01.008.

[69] N. Sudarmadji, J.Y. Tan, K.F. Leong, C.K. Chua, Y.T. Loh, Investigation of the mechanical properties and porosity relationships in selective laser-sintered polyhedral for functionally graded scaffolds, Acta Biomater. 7 (2011) 530-537. doi:10.1016/j.actbio.2010.09.024.

[70] J. Li, C. Diansheng, F. Yubo, Evaluation and Prediction of Mass Transport Properties for Porous Implant with Different Unit Cells: A Numerical Study, Biomed Res. Int. 2019 (2019) 11.

https://www.hindawi.com/journals/bmri/2019/3610785/.

[71] W. Wen, P. Somasundaram, C. Raymond, Unraveling the mechanical strength of biomaterials used as a bone scaffold in oral and maxillofacial defects, Oral Sci. Int. 15 (2018) 48-55.

[72] S. Ponader, C. Wilmowsky, M. Widenmayer, R. Heinl, C. Körner, R. Singer, E. Nkenke, F. Neukam, K. A, In vivo performance of selective electron beam-melted Ti-6Al-4V structures, Biomed. M Aterial Res. (2009) 56-62. doi:10.1002/jbm.a.32337.

[73] C. Chen, Y. Hao, X. Bai, J. Ni, S.-M. Chung, F. Liu, I.-S. Lee, 3D printed porous Ti6Al4V cage: Effects of additive angle on surface properties and biocompatibility bone ingrowth in Beagle tibia model, Mater. Des. Des. 175 (2019) 107824. https://www.sciencedirect.com/science/article/pii/S0264127519302618.

[74] O.A. Yoram Mass, Topology optimization for additive manufacturing: Accounting for overhang limitations using a virtual skeleton, Addit. Manuf. 18 (2017) 58-73. doi:doi.org/10.1016/j.addma.2017.08.001.

[75] P.F. Egan, V.C. Gonella, M. Engensperger, S.J. Ferguson, K. Shea, Computationally designed lattices with tuned properties for tissue engineering using 3D printing, PLoS One. 12 (2017) e0182902. doi:10.1371/journal.pone.0182902.

[76] Y. Kang, J. Chang, Channels in a porous scaffold: A new player for vascularization, Regen. Med. 13 (2018) 705-715. doi:10.2217/rme-2018-0022.

[77] X. Chen, H. Fan, X. Deng, L. Wu, T. Yi, L. Gu, C. Zhou, Y. Fan, X. Zhang, X. Chen, H. Fan, X. Deng, L. Wu, T. Yi, L. Gu, C. Zhou, Y. Fan, X. Zhang, Scaffold Structural Microenvironmental Cues to Guide Tissue Regeneration in Bone Tissue Applications, Nanomaterials. 8 (2018) 960. doi:10.3390/nano8110960.

[78] J. Wieding, A. Jonitz, R. Bader, The effect of structural design on mechanical properties and cellular response of additive manufactured titanium scaffolds, Materials (Basel). 5 (2012) 1336-1347. doi:10.3390/ma5081336.

[79] E.H. Schemitsch, Size Matters: Defining Critical in Bone Defect Size!, J. Orthop. Trauma. 31 (2017) S20-S22. doi:10.1097/BOT.0000000000000978.

[80] D.N. Utomo, K.D. Hernugrahanto, M. Edward, L. Widhiyanto, F. Mahyudin, Combination of Bone Marrow Aspirate, Cancellous Bone Allograft, and Platelet-rich Plasma as an Alternative Solution to Critical-sized Diaphyseal Bone Defect: A Case Series, Int. J. Surg. Case Rep. 58 (2019) 178-185. doi:10.1016/j.ijscr.2019.04.028.

[81] C. Christou, R.A. Oliver, M.H. Pelletier, W.R. Walsh, Ovine model for critical-size tibial segmental defects., Comp. Med. 64 (2014) 377-85. https://www.ncbi.nlm.nih.gov/pubmed/25402178.

[82] F. Zhao, T.J. Vaughan, L.M. McNamara, Quantification of fluid shear stress in bone tissue engineering scaffolds with spherical and cubical pore architectures, Biomech. Model. Mechanobiol. 15 (2016) 561-577. doi:10.1007/s10237-015-0710- 
[83] S.P. Singh, M. Shukla, R.K. Srivastava, Lattice Modeling and CFD Simulation for Prediction of Permeability in Porous Scaffolds, Mater. Today Proc. 5 (2018) 18879-18886. doi:10.1016/J.MATPR.2018.06.236.

[84] P. Vossenberg, G.A. Higuera, G. van Straten, C.A. van Blitterswijk, A.J.B. van Boxtel, Darcian permeability constant as indicator for shear stresses in regular scaffold systems for tissue engineering, Biomech. Model. Mechanobiol. 8 (2009) 499507. doi:10.1007/s10237-009-0153-6.

[85] X. Xue, M.K. Patel, M. Kersaudy-Kerhoas, M.P.Y. Desmulliez, C. Bailey, D. Topham, Analysis of fluid separation in microfluidic T-channels, Appl. Math. Model. 36 (2012) 743-755. doi:10.1016/j.apm.2011.07.009.

[86] A. Arjunan, C. Wang, M. English, M. Stanford, P. Lister, A computationally-efficient numerical model to characterize the noise behavior of metal-framed walls, Metals (Basel). 5 (2015) 1414-1431. doi:10.3390/met5031414.

[87] A. Arjunan, C.J. Wang, K. Yahiaoui, D.J. Mynors, T. Morgan, V.B. Nguyen, M. English, Sound frequency dependent mesh modelling to simulate the acoustic insulation of stud based double-leaf walls, in: Proc. ISMA 2014 - Int. Conf. Noise Vib. Eng. USD 2014 - Int. Conf. Uncertain. Struct. Dyn., 2014.

[88] A. Arjunan, A. Foteinou, A comparative study on the acoustic behaviour of free-standing curved and flat single panel screens in an open-plan enclosed environment, in: INTER-NOISE 2017 - 46th Int. Congr. Expo. Noise Control Eng. Taming Noise Mov. Quiet, 2017.

[89] A. Arjunan, Sound transmission loss of light-weight slotted steel studs in a gypsum plasterboard partition wall, in: Proc. INTER-NOISE 2016 - 45th Int. Congr. Expo. Noise Control Eng. Towar. a Quieter Futur., 2016.

[90] D. Ali, S. Sen, Finite element analysis of mechanical behavior, permeability and fluid induced wall shear stress of high porosity scaffolds with gyroid and lattice-based architectures, J. Mech. Behav. Biomed. Mater. 75 (2017) 262-270. doi:10.1016/j.jmbbm.2017.07.035.

[91] A.R. Pombinho, V. Laizé, D.M. Molha, S.M.P. Marques, M.L. Cancela, Development of two bone-derived cell lines from the marine teleost Sparus aurata; evidence for extracellular matrix mineralization and cell-type-specific expression of matrix Gla protein and osteocalcin, Cell Tissue Res. 315 (2004) 393-406. doi:10.1007/s00441-003-0830-1.

[92] BS EN ISO 6892-1:2016., BS EN ISO 6892-1:2016. Metallic materials. Tensile testing. Method of test at room temperature., 2016. https://bsol-bsigroup-com.ezproxy.wlv.ac.uk/Search/Search?searchKey=bs+en+iso+68921\%3A2016\&OriginPage $=$ Header + Search+Box\&autoSuggestion=true (accessed August 6, 2019) .

[93] N. Velisavljevic, G.N. Chesnut, Direct hcp $\rightarrow$ bcc structural phase transition observed in titanium alloy at high pressure, Appl. Phys. Lett. 91 (2007) 101906. doi:10.1063/1.2780078.

[94] A.R. McAndrew, M. Alvarez Rosales, P.A. Colegrove, J.R. Hönnige, A. Ho, R. Fayolle, K. Eyitayo, I. Stan, P. Sukrongpang, A. Crochemore, Z. Pinter, Interpass rolling of Ti-6Al-4V wire + arc additively manufactured features for microstructural refinement, Addit. Manuf. 21 (2018) 340-349. doi:10.1016/J.ADDMA.2018.03.006.

[95] A. Pesach, E. Tiferet, S.C. Vogel, M. Chonin, A. Diskin, L. Zilberman, O. Rivin, O. Yeheskel, E.N. Caspi, Texture analysis of additively manufactured Ti-6Al-4V using neutron diffraction, Addit. Manuf. 23 (2018) 394-401. doi:10.1016/J.ADDMA.2018.08.010.

[96] J.M. Lee, S.L. Sing, M. Zhou, W.Y. Yeong, 3D bioprinting processes: A perspective on classification and terminology, Int. J. Bioprinting. 4 (2018). doi:10.18063/ijb.v4i2.151.

[97] ISO/ASTM 52900:2017, Additive manufacturing — General principles — Terminology (ISO/ASTM 52900:2017), BSI Stand. Publ. (2017).

[98] R. Wauthle, B. Vrancken, B. Beynaerts, K. Jorissen, J. Schrooten, J.-P.J.-P. Kruth, J. Van Humbeeck, Effects of build orientation and heat treatment on the microstructure and mechanical properties of selective laser melted Ti6Al4V lattice structures, Addit. Manuf. 5 (2015) 77-84. doi:10.1016/j.addma.2014.12.008.

[99] ISO 7500-1:2018 - Metallic materials -- Calibration and verification of static uniaxial testing machines -- Part 1: Tension/compression testing machines -- Calibration and verification of the force-measuring system, 2018. https://www.iso.org/standard/72572.html (accessed January 28, 2019).

[100] BS ISO 13314:2011, BS ISO 13314:2011. Mechanical testing of metals. Ductility testing. Compression test for porous and cellular metals., 2011. https://bsol.bsigroup.com/Bibliographic/BibliographicInfoData/000000000030203544 (accessed August 8, 2019). 
[101] K.B. Hazlehurst, C.J. Wang, M. Stanford, An investigation into the flexural characteristics of functionally graded cobalt chrome femoral stems manufactured using selective laser melting, Mater. Des. 60 (2014) 177-183. doi:10.1016/j.matdes.2014.03.068.

[102] A. Entezari, I. Roohani, G. Li, C.R. Dunstan, P. Rognon, Q. Li, X. Jiang, H. Zreiqat, Architectural Design of 3D Printed Scaffolds Controls the Volume and Functionality of Newly Formed Bone, Adv. Healthc. Mater. 8 (2018) 1801353. doi:10.1002/adhm.201801353.

[103] M. Mastrogiacomo, S. Scaglione, R. Martinetti, L. Dolcini, F. Beltrame, R. Cancedda, R. Quarto, Role of scaffold internal structure on in vivo bone formation in macroporous calcium phosphate bioceramics, Biomaterials. 27 (2006) 3230-3237. doi:10.1016/J.BIOMATERIALS.2006.01.031.

[104] F.S.L. Bobbert, A.A. Zadpoor, Effects of bone substitute architecture and surface properties on cell response, angiogenesis, and structure of new bone, J. Mater. Chem. B. 5 (2017) 6175-6192. doi:10.1039/C7TB00741H.

[105] V. Karageorgiou, D. Kaplan, Porosity of 3D biomaterial scaffolds and osteogenesis, Biomaterials. 26 (2005) 5474-5491. doi:10.1016/j.biomaterials.2005.02.002.

[106] I. Ochoa, J.A. Sanz-Herrera, J.M. García-Aznar, M. Doblaré, D.M. Yunos, A.R. Boccaccini, Permeability evaluation of 45S5 Bioglass@-based scaffolds for bone tissue engineering, J. Biomech. 42 (2009) 257-260. doi:10.1016/j.jbiomech.2008.10.030.

[107] Z. Wang, C. Huang, J. Wang, P. Wang, S. Bi, C.A. Abbas, Design and Simulation of Flow Field for Bone Tissue Engineering Scaffold Based on Triply Periodic Minimal Surface, Chinese J. Mech. Eng. 32 (2019) 19. doi:10.1186/s10033019-0329-7.

[108] A.A. Zadpoor, Bone tissue regeneration: the role of scaffold geometry, Biomater. Sci. 3 (2015) 231-245. doi:10.1039/C4BM00291A.

[109] J. Knychala, N. Bouropoulos, C.J. Catt, O.L. Katsamenis, C.P. Please, B.G. Sengers, Pore Geometry Regulates Early Stage Human Bone Marrow Cell Tissue Formation and Organisation, Ann. Biomed. Eng. 41 (2013) 917-930. doi:10.1007/s10439-013-0748-z.

[110] E.A. Nauman, K.E. Fong, T.M. Keaveny, Dependence of Intertrabecular Permeability on Flow Direction and Anatomic Site, Ann. Biomed. Eng. 27 (1999) 517-524. doi:10.1114/1.195.

[111] D.P. Byrne, D. Lacroix, J.A. Planell, D.J. Kelly, P.J. Prendergast, Simulation of tissue differentiation in a scaffold as a function of porosity, Young's modulus and dissolution rate: Application of mechanobiological models in tissue engineering, Biomaterials. 28 (2007) 5544-5554. doi:10.1016/j.biomaterials.2007.09.003.

[112] B.G. Sengers, M. Taylor, C.P. Please, R.O.C. Oreffo, Computational modelling of cell spreading and tissue regeneration in porous scaffolds, Biomaterials. 28 (2007) 1926-1940. doi:10.1016/J.BIOMATERIALS.2006.12.008.

[113] V.S. Deshpande, M.F. Ashby, N.A. Fleck, Foam topology: Bending versus stretching dominated architectures, Acta Mater. 49 (2001) 1035-1040. doi:10.1016/S1359-6454(00)00379-7.

[114] A. Arjunan, A. Baroutaji, A.S. Praveen, A.G. Olabi, C.J. Wang, Acoustic Performance of Metallic Foams, in: Ref. Modul. Mater. Sci. Mater. Eng., Elsevier, 2019. doi:10.1016/B978-0-12-803581-8.11561-9.

[115] J. Xu, Y. Wu, L. Wang, J. Li, Y. Yang, Y. Tian, Z. Gong, P. Zhang, S. Nutt, S. Yin, Compressive properties of hollow lattice truss reinforced honeycombs (Honeytubes) by additive manufacturing: Patterning and tube alignment effects, Mater. Des. 156 (2018) 446-457. doi:10.1016/J.MATDES.2018.07.019.

[116] B.K. Hoffmeister, S.R. Smith, S.M. Handley, J.Y. Rho, Anisotropy of Young's modulus of human tibial cortical bone., Med. Biol. Eng. Comput. 38 (2000) 333-8. http://www.ncbi.nlm.nih.gov/pubmed/10912351 (accessed August 9, 2019).

[117] J. Rho, R. Ashman, C. Turner, Young's modulus of trabecular and cortical bone material: Ultrasonic and microtensile measurements, J. Biomech. 26 (1993) 111-119. doi:10.1016/0021-9290(93)90042-D.

[118] P.K. Zysset, X. Edward Guo, C. Edward Hoffler, K.E. Moore, S.A. Goldstein, Elastic modulus and hardness of cortical and trabecular bone lamellae measured by nanoindentation in the human femur, J. Biomech. 32 (1999) 1005-1012. doi:10.1016/S0021-9290(99)00111-6.

[119] M. Kaur, K. Singh, Review on titanium and titanium based alloys as biomaterials for orthopaedic applications, Mater. Sci. Eng. C. 102 (2019) 844-862. doi:10.1016/J.MSEC.2019.04.064.

[120] M. Mahbod, M. Asgari, Elastic and plastic characterization of a new developed additively manufactured functionally 
graded porous lattice structure: Analytical and numerical models, Int. J. Mech. Sci. 155 (2019) 248-266. doi:10.1016/J.IJMECSCI.2019.02.041.

[121] N.H. Pham, R.S. Voronov, S.B. Vangordon, V.I. Sikavitsas, D. V Papavassiliou, Predicting the stress distribution within scaffolds with ordered architecture., Biorheology. 49 (2012) 235-47. doi:10.3233/BIR-2012-0613.

[122] S. Campanelli, N. Contuzzi, A. Ludovico, F. Caiazzo, F. Cardaropoli, V. Sergi, Manufacturing and Characterization of Ti6Al4V Lattice Components Manufactured by Selective Laser Melting, Materials (Basel). 7 (2014) 4803-4822. doi: $10.3390 / \mathrm{ma} 7064803$.

[123] N. Soro, H. Attar, X. Wu, M.S. Dargusch, Investigation of the structure and mechanical properties of additively manufactured Ti-6Al-4V biomedical scaffolds designed with a Schwartz primitive unit-cell, Mater. Sci. Eng. A. 745 (2019) 195-202. doi:10.1016/j.msea.2018.12.104.

[124] R. Singh, P.D. Lee, T.C. Lindley, C. Kohlhauser, C. Hellmich, M. Bram, T. Imwinkelried, R.J. Dashwood, Characterization of the deformation behavior of intermediate porosity interconnected Ti foams using micro-computed tomography and direct finite element modeling, Acta Biomater. 6 (2010) 2342-2351. doi:10.1016/j.actbio.2009.11.032.

[125] W.J. Hendrikson, C.A. van Blitterswijk, J. Rouwkema, L. Moroni, The Use of Finite Element Analyses to Design and Fabricate Three-Dimensional Scaffolds for Skeletal Tissue Engineering, Front. Bioeng. Biotechnol. 5 (2017) 30. doi:10.3389/fbioe.2017.00030.

[126] S.J. Li, L.E. Murr, X.Y. Cheng, Z.B. Zhang, Y.L. Hao, R. Yang, F. Medina, R.B. Wicker, Compression fatigue behavior of Ti-6Al-4V mesh arrays fabricated by electron beam melting, Acta Mater. 60 (2012) 793-802. doi:10.1016/j.actamat.2011.10.051.

[127] H. Wang, D. Gu, K. Lin, L. Xi, L. Yuan, Compressive Properties of Bio-Inspired Reticulated Shell Structures Processed by Selective Laser Melting, Adv. Eng. Mater. 21 (2019) 1801168. doi:10.1002/adem.201801168.

[128] M. Santorinaios, W. Brooks, C.J. Sutcliffe, R.A.W. Mines, Crush Behaviour Of Open Cellular LatticeStructures Manufactured UsingSelective Laser Melting, WIT Trans. Built Environ. 85 (2006). doi:10.2495/HPSM060471.

[129] L.E. Murr, S.M. Gaytan, F. Medina, E. Martinez, J.L. Martinez, D.H. Hernandez, B.I. Machado, D.A. Ramirez, R.B. Wicker, Characterization of Ti-6Al-4V open cellular foams fabricated by additive manufacturing using electron beam melting, Mater. Sci. Eng. A. 527 (2010) 1861-1868. doi:10.1016/j.msea.2009.11.015.

[130] E. Hernández-Nava, C.J. Smith, F. Derguti, S. Tammas-Williams, F. Léonard, P.J. Withers, I. Todd, R. Goodall, The effect of density and feature size on mechanical properties of isostructural metallic foams produced by additive manufacturing, Acta Mater. 85 (2015) 387-395. doi:10.1016/j.actamat.2014.10.058.

[131] G. Maliaris, E. Sarafis, Mechanical Behavior of 3D Printed Stochastic Lattice Structures, Solid State Phenom. 258 (2016) 225-228. doi:10.4028/www.scientific.net/SSP.258.225.

[132] S.L. Sing, W.Y. Yeong, F.E. Wiria, B.Y. Tay, Characterization of Titanium Lattice Structures Fabricated by Selective Laser Melting Using an Adapted Compressive Test Method, Exp. Mech. 56 (2016) 735-748. doi:10.1007/s11340-015-0117$\mathrm{y}$.

[133] M. De Wild, R. Schumacher, K. Mayer, E. Schkommodau, D. Thoma, M. Bredell, A. Kruse Gujer, K.W. Grätz, F.E. Weber, Bone regeneration by the osteoconductivity of porous titanium implants manufactured by selective laser melting: A histological and micro computed tomography study in the rabbit, Tissue Eng. - Part A. 19 (2013) 2645-2654. doi:10.1089/ten.tea.2012.0753.

[134] F. Liu, Z. Mao, P. Zhang, D.Z. Zhang, J. Jiang, Z. Ma, Functionally graded porous scaffolds in multiple patterns: New design method, physical and mechanical properties, Mater. Des. 160 (2018) 849-860. doi:10.1016/j.matdes.2018.09.053.

[135] M. Speirs, B. Van Hooreweder, J. Van Humbeeck, J.-P. Kruth, Fatigue behaviour of NiTi shape memory alloy scaffolds produced by SLM, a unit cell design comparison, J. Mech. Behav. Biomed. Mater. 70 (2017) 53-59. doi:10.1016/j.jmbbm.2017.01.016.

[136] L. Wang, J. Kang, C. Sun, D. Li, Y. Cao, Z. Jin, Mapping porous microstructures to yield desired mechanical properties for application in 3D printed bone scaffolds and orthopaedic implants, Mater. Des. 133 (2017) 62-68. doi:10.1016/j.matdes.2017.07.021.

[137] L. Podshivalov, C.M. Gomes, A. Zocca, J. Guenster, P. Bar-Yoseph, A. Fischer, Design, analysis and additive manufacturing of porous structures for biocompatible micro-scale scaffolds, in: First CIRP Conf. Biomanufacturing, Elsevier, 2013: pp. 247-252. doi:10.1016/j.procir.2013.01.049. 
[138] Y. An, C.H. Yang, P.D. Hodgson, C.E. Wen, Effect of Pore Size on Mechanical Properties of Titanium Foams, Mater. Sci. Forum. 654-656 (2010) 827-830. doi:10.4028/www.scientific.net/MSF.654-656.827.

[139] Z. Zhang, H. Li, G.R. Fogel, Z. Liao, Y. Li, W. Liu, Biomechanical Analysis of Porous Additive Manufactured Cages for Lateral Lumbar Interbody Fusion: A Finite Element Analysis, World Neurosurg. 111 (2018) e581-e591. doi:10.1016/J.WNEU.2017.12.127.

[140] D. Luo, Q. Rong, Q. Chen, Finite-element design and optimization of a three-dimensional tetrahedral porous titanium scaffold for the reconstruction of mandibular defects, Med. Eng. Phys. 47 (2017) 176-183. doi:10.1016/J.MEDENGPHY.2017.06.015.

[141] S. Roy, N. Khutia, D. Das, M. Das, V.K. Balla, A. Bandyopadhyay, A.R. Chowdhury, Understanding compressive deformation behavior of porous Ti using finite element analysis, Mater. Sci. Eng. C. 64 (2016) 436-443. doi:10.1016/J.MSEC.2016.03.066.

[142] H. Shen, L.C. Brinson, Finite element modeling of porous titanium, Int. J. Solids Struct. 44 (2007) 320-335. doi:10.1016/j.jjsolstr.2006.04.020.

[143] O. Harrysson, O. Cansizoglu, D. Marcellin-Little, D. Cormier, H. West, Direct metal fabrication of titanium implants with tailored materials and mechanical properties using electron beam melting technology, Mater. Sci. Eng. C. 28 (2008) 366-373. doi:10.1016/j.msec.2007.04.022.

[144] K. Hazlehurst, C.J. Wang, M. Stanford, Evaluation of the stiffness characteristics of square pore CoCrMo cellular structures manufactured using laser melting technology for potential orthopaedic applications, Mater. Des. 51 (2013) 949-955. doi:10.1016/j.matdes.2013.05.009.

[145] H.H. Alsalla, C. Smith, L. Hao, The effect of different build orientations on the consolidation, tensile and fracture toughness properties of direct metal laser sintering Ti-6Al-4V, Rapid Prototyp. J. 24 (2018) 276-284. doi:10.1108/RPJ04-2016-0067.

[146] W.M. Chen, S.J. Lee, P.V.S. Lee, Failure Analysis of an Additive Manufactured Porous Titanium Structure for Orthopedic Implant Applications, Mater. Sci. Forum. 863 (2016) 45-49. doi:10.4028/www.scientific.net/MSF.863.45.

[147] Z. Wahid, M.K.A.M. Ariffin, B.T.H.T. Baharudin, M.I.S. Ismail, F. Mustapha, Abaqus Simulation of Different Critical Porosities Cubical Scaffold Model, IOP Conf. Ser. Mater. Sci. Eng. 530 (2019) 012018. doi:10.1088/1757899X/530/1/012018.

[148] A. Salimon, Y. Bréchet, M.F. Ashby, A.L. Greer, Potential applications for steel and titanium metal foams, J. Mater. Sci. 40 (2005) 5793-5799. doi:10.1007/s10853-005-4993-x.

[149] J. Favre, P. Lohmuller, B. Piotrowski, S. Kenzari, P. Laheurte, F. Meraghni, A continuous crystallographic approach to generate cubic lattices and its effect on relative stiffness of architectured materials, Addit. Manuf. 21 (2018) 359-368. doi:10.1016/j.addma.2018.02.020.

[150] G. Savio, S. Rosso, A. Curtarello, R. Meneghello, G. Concheri, Implications of modeling approaches on the fatigue behavior of cellular solids, Addit. Manuf. 25 (2019) 50-58. doi:10.1016/j.addma.2018.10.047.

[151] L. Marsavina, E. Linul, T. Voiconi, R. Negru, Experimental investigations and numerical simulations of notch effect in cellular plastic materials, IOP Conf. Ser. Mater. Sci. Eng. 123 (2016) 012060. doi:10.1088/1757-899X/123/1/012060.

[152] Y. Murakami, Stress concentration, Met. Fatigue. (2019) 13-27. doi:10.1016/B978-0-12-813876-2.00002-9.

[153] N.-A. Noda, Y. Shen, R. Takaki, D. Akagi, T. Ikeda, Y. Sano, Y. Takase, Relationship between strain rate concentration factor and stress concentration factor, Theor. Appl. Fract. Mech. 90 (2017) 218-227. doi:10.1016/J.TAFMEC.2017.05.017.

[154] A.R. Boccaccini, G. Ondracek, E. Mombello, Determination of stress concentration factors in porous materials, J. Mater. Sci. Lett. 15 (n.d.) 534-536. doi:10.1007/bf00275423.

[155] I.F. Zuñiga Tello, G.M. Domínguez Almaraz, V. López Garza, M. Guzmán Tapia, Numerical investigation of the stress concentration on 7075-T651 aluminum alloy with one or two hemispherical pits under uniaxial or biaxial loading, Adv. Eng. Softw. 131 (2019) 23-35. doi:10.1016/J.ADVENGSOFT.2018.09.013.

[156] D.W. Abueidda, M. Elhebeary, C.-S. (Andrew) Shiang, S. Pang, R.K. Abu Al-Rub, I.M. Jasiuk, Mechanical properties of 3D printed polymeric Gyroid cellular structures: Experimental and finite element study, Mater. Des. 165 (2019). doi:10.1016/j.matdes.2019.107597. 
[157] H.E. Burton, N.M. Eisenstein, B.M. Lawless, P. Jamshidi, M.A. Segarra, O. Addison, D.E.T. Shepherd, M.M. Attallah, L.M. Grover, S.C. Cox, The design of additively manufactured lattices to increase the functionality of medical implants, Mater. Sci. Eng. C. 94 (2019) 901-908. doi:10.1016/j.msec.2018.10.052.

[158] L. Feng, D.J. Milner, C. Xia, H.L.D. Nye, P. Redwood, J.A. Cameron, D.L. Stocum, N. Fang, I. Jasiuk, Xenopus laevis as a novel model to study long bone critical-size defect repair by growth factor-mediated regeneration., Tissue Eng. Part A. 17 (2011) 691-701. doi:10.1089/ten.TEA.2010.0123.

[159] A.R. Vaccaro, The role of the osteoconductive scaffold in synthetic bone graft., Orthopedics. 25 (2002) s571-8. http://www.ncbi.nlm.nih.gov/pubmed/12038844 (accessed August 11, 2019).

[160] L.-J. Li, N. Liu, J.-G. Shi, Q. Liu, L.-S. Jia, W. Yuan, Osteogenic scaffolds for bone reconstruction., Biores. Open Access. 1 (2012) 137-44. doi:10.1089/biores.2012.0226.

[161] O. Tsigkou, I. Pomerantseva, J.A. Spencer, P.A. Redondo, A.R. Hart, E. O'Doherty, Y. Lin, C.C. Friedrich, L. Daheron, C.P. Lin, C.A. Sundback, J.P. Vacanti, C. Neville, Engineered vascularized bone grafts., Proc. Natl. Acad. Sci. U. S. A. 107 (2010) 3311-6. doi:10.1073/pnas.0905445107.

[162] T. Guda, M. Appleford, S. Oh, J.L. Ong, A cellular perspective to bioceramic scaffolds for bone tissue engineering: the state of the art., Curr. Top. Med. Chem. 8 (2008) 290-9. http://www.ncbi.nlm.nih.gov/pubmed/18393892 (accessed August 11, 2019).

[163] A.M.M. Amin, E.M.M. Ewais, Bioceramic Scaffolds, in: Scaffolds Tissue Eng. - Mater. Technol. Clin. Appl., InTech, 2017. doi:10.5772/intechopen.70194.

[164] F. Baino, G. Novajra, C. Vitale-Brovarone, Bioceramics and Scaffolds: A Winning Combination for Tissue Engineering., Front. Bioeng. Biotechnol. 3 (2015) 202. doi:10.3389/fbioe.2015.00202.

[165] I. Titorencu, M. Albu, M. Nemecz, V. Jinga, Natural Polymer-Cell Bioconstructs for Bone Tissue Engineering, Curr. Stem Cell Res. Ther. 12 (2016) 165-174. doi:10.2174/1574888X10666151102105659.

[166] X. Liu, P.X. Ma, Polymeric scaffolds for bone tissue engineering., Ann. Biomed. Eng. 32 (2004) 477-86. http://www.ncbi.nlm.nih.gov/pubmed/15095822 (accessed August 11, 2019).

[167] M. Meskinfam, Polymer scaffolds for bone regeneration, Charact. Polym. Biomater. (2017) 441-475. doi:10.1016/B978-008-100737-2.00017-0.

[168] S. Impens, Y. Chen, S. Mullens, F. Luyten, J. Schrooten, Controlled Cell-Seeding Methodologies: A First Step Toward Clinically Relevant Bone Tissue Engineering Strategies, Tissue Eng. Part C Methods. 16 (2010) 1575-1583. doi:10.1089/ten.tec.2010.0069.

[169] B.V. Krishna, S. Bose, A. Bandyopadhyay, Low stiffness porous Ti structures for load-bearing implants, Acta Biomater. 3 (2007) 997-1006. doi:10.1016/j.actbio.2007.03.008.

[170] P. Heinl, L.L. Müller, C. Körner, R.F. Singer, F.A. Müller, Cellular Ti-6Al-4V structures with interconnected macro porosity for bone implants fabricated by selective electron beam melting, Acta Biomater. 4 (2008) 1536-1544. doi:10.1016/j.actbio.2008.03.013.

[171] S.L. Sing, J. An, W.Y. Yeong, F.E. Wiria, Laser and electron-beam powder-bed additive manufacturing of metallic implants: A review on processes, materials and designs, J. Orthop. Res. 34 (2016) 369-385. doi:10.1002/jor.23075.

[172] G. Ryan, A. Pandit, D.P.D.P. Apatsidis, Fabrication methods of porous metals for use in orthopaedic applications, Biomaterials. 27 (2006) 2651-2670. doi:10.1016/j.biomaterials.2005.12.002.

[173] D. Ali, S. Sen, Permeability and fluid flow-induced wall shear stress of bone tissue scaffolds: Computational fluid dynamic analysis using Newtonian and non-Newtonian blood flow models, Comput. Biol. Med. 99 (2018) 201-208. doi:10.1016/j.compbiomed.2018.06.017.

[174] F.J. O'Brien, B.A. Harley, M.A. Waller, I. V Yannas, L.J. Gibson, P.J. Prendergast, The effect of pore size on permeability and cell attachment in collagen scaffolds for tissue engineering., Technol. Health Care. 15 (2007) 3-17. http://www.ncbi.nlm.nih.gov/pubmed/17264409 (accessed June 4, 2019).

[175] R.J. McCoy, C. Jungreuthmayer, Influence of flow rate and scaffold pore size on cell behavior during mechanical stimulation in a flow perfusion bioreactor. Citation, Biotechnol Bioeng. 109 (2012) 1583-94. http://epubs.rcsi.ie/anatart/51 (accessed June 4, 2019).

[176] S. Limmahakhun, A. Oloyede, K. Sitthiseripratip, Y. Xiao, C. Yan, Stiffness and strength tailoring of cobalt chromium 
graded cellular structures for stress-shielding reduction, Mater. Des. 114 (2017) 633-641. doi:10.1016/j.matdes.2016.11.090.

[177] R.C. Huiskes, H. Weinans, B.V. Rietbergen, The Relationship Between Stress Shielding and Bone Resorption Around Total Hip Stems and the Effects of Flexible Materials, Clin. Orthop. Relat. Res. Jan (1992) 124-34. doi:10.1097/00003086-199201000-00014.

[178] S. Arabnejad, B. Johnston, M. Tanzer, D. Pasini, Fully porous 3D printed titanium femoral stem to reduce stressshielding following total hip arthroplasty, J. Orthop. Res. 35 (2017) 1774-1783. doi:10.1002/jor.23445.

[179] D. Ali, S. Sen, Finite element analysis of boron nitride nanotubes' shielding effect on the stress intensity factor of semielliptical surface crack in a wide range of matrixes using RVE model, Compos. Part B Eng. 110 (2017) 351-360. doi:10.1016/j.compositesb.2016.11.017.

[180] D.D. Lima, S.A. Mantri, C.V. Mikler, R. Contieri, C.J. Yannetta, K.N. Campo, E.S. Lopes, M.J. Styles, T. Borkar, R. Caram, R. Banerjee, Laser additive processing of a functionally graded internal fracture fixation plate, Mater. Des. 130 (2017) 8-15. doi:10.1016/j.matdes.2017.05.034.

[181] X.P. Tan, Y.J. Tan, C.S.L. Chow, S.B. Tor, W.Y. Yeong, Metallic powder-bed based 3D printing of cellular scaffolds for orthopaedic implants: A state-of-the-art review on manufacturing, topological design, mechanical properties and biocompatibility, Mater. Sci. Eng. C. 76 (2017) 1328-1343. doi:10.1016/j.msec.2017.02.094.

[182] J. Čapek, M. Machová, M. Fousová, J. Kubásek, D. Vojtěch, J. Fojt, E. Jablonská, J. Lipov, T. Ruml, Highly porous, low elastic modulus 316L stainless steel scaffold prepared by selective laser melting, Mater. Sci. Eng. C. 69 (2016) 631639. doi:10.1016/j.msec.2016.07.027.

[183] S. Eshraghi, S. Das, Micromechanical finite-element modeling and experimental characterization of the compressive mechanical properties of polycaprolactone-hydroxyapatite composite scaffolds prepared by selective laser sintering for bone tissue engineering, Acta Biomater. 8 (2012) 3138-3143. doi:10.1016/j.actbio.2012.04.022.

[184] W.-M. Chen, Y.M. Xie, G. Imbalzano, J. Shen, S. Xu, S.-J. Lee, P.V.S. Lee, Lattice Ti structures with low rigidity but compatible mechanical strength: Design of implant materials for trabecular bone, Int. J. Precis. Eng. Manuf. 17 (2016) 793-799. doi:10.1007/s12541-016-0097-6.

[185] A. Yánez, A. Cuadrado, O. Martel, H. Afonso, D. Monopoli, Gyroid porous titanium structures: A versatile solution to be used as scaffolds in bone defect reconstruction, Mater. Des. 140 (2018) 21-29. doi:10.1016/J.MATDES.2017.11.050.

[186] X. Zheng, H. Lee, T.H. Weisgraber, M. Shusteff, J. DeOtte, E.B. Duoss, J.D. Kuntz, M.M. Biener, Q. Ge, J.A. Jackson, S.O. Kucheyev, N.X. Fang, C.M. Spadaccini, Ultralight, ultrastiff mechanical metamaterials, Science (80-. ). 344 (2014) 1373-1377. doi:10.1126/science.1252291.

[187] J.D. Currey, Stress Concentrations in Bone, J. Cell Sci. s3-103 (1962) 111-133. https://jcs.biologists.org/content/s3103/61/111 (accessed August 11, 2019).

[188] R. Patel, M. Lu, S.H. Diermann, A. Wu, A. Pettit, H. Huang, Deformation behavior of porous PHBV scaffold in compression: A finite element analysis study, J. Mech. Behav. Biomed. Mater. 96 (2019) 1-8. doi:10.1016/j.jmbbm.2019.04.030

[189] N. Uth, J. Mueller, B. Smucker, A.-M. Yousefi, Validation of scaffold design optimization in bone tissue engineering: finite element modeling versus designed experiments, Biofabrication. 9 (2017) 015023. doi:10.1088/1758-5090/9/1/015023.

[190] W.J. Hendrikson, A.J. Deegan, Y. Yang, C.A. van Blitterswijk, N. Verdonschot, L. Moroni, J. Rouwkema, Influence of Additive Manufactured Scaffold Architecture on the Distribution of Surface Strains and Fluid Flow Shear Stresses and Expected Osteochondral Cell Differentiation, Front. Bioeng. Biotechnol. 5 (2017). doi:10.3389/fbioe.2017.00006.

[191] C. Sandino, J.A. Planell, D. Lacroix, A finite element study of mechanical stimuli in scaffolds for bone tissue engineering, J. Biomech. 41 (2008) 1005-1014. doi:10.1016/j.jbiomech.2007.12.011.

[192] C. Sandino, D. Lacroix, A dynamical study of the mechanical stimuli and tissue differentiation within a CaP scaffold based on micro-CT finite element models, Biomech. Model. Mechanobiol. 10 (2011) 565-576. doi:10.1007/s10237-0100256-0.

[193] Z. Chen, X. Wu, D. Tomus, C.H.J. Davies, Surface roughness of Selective Laser Melted Ti-6Al-4V alloy components, Addit. Manuf. 21 (2018) 91-103. doi:10.1016/J.ADDMA.2018.02.009.

[194] S. Cahill, S. Lohfeld, P.E. McHugh, Finite element predictions compared to experimental results for the effective modulus of bone tissue engineering scaffolds fabricated by selective laser sintering, J. Mater. Sci. Mater. Med. 20 (2009) 
1255-1262. doi:10.1007/s10856-009-3693-5.

[195] H. Doyle, S. Lohfeld, P. McHugh, Predicting the Elastic Properties of Selective Laser Sintered PCL/ $\beta$-TCP Bone Scaffold Materials Using Computational Modelling, Ann. Biomed. Eng. 42 (2014) 661-677. doi:10.1007/s10439-013-09134 .

[196] E.B. Duoss, T.H. Weisgraber, K. Hearon, C. Zhu, W. Small, T.R. Metz, J.J. Vericella, H.D. Barth, J.D. Kuntz, R.S. Maxwell, C.M. Spadaccini, T.S. Wilson, Three-Dimensional Printing of Elastomeric, Cellular Architectures with Negative Stiffness, Adv. Funct. Mater. 24 (2014) 4905-4913. doi:10.1002/adfm.201400451.

[197] S. Barui, S. Chatterjee, S. Mandal, A. Kumar, B. Basu, Microstructure and compression properties of 3D powder printed Ti-6Al-4V scaffolds with designed porosity: Experimental and computational analysis, Mater. Sci. Eng. C. 70 (2017) 812823. doi:10.1016/j.msec.2016.09.040.

[198] M.R. Karamooz Ravari, M. Kadkhodaei, M. Badrossamay, R. Rezaei, Numerical investigation on mechanical properties of cellular lattice structures fabricated by fused deposition modeling, Int. J. Mech. Sci. 88 (2014) 154-161. doi:10.1016/j.ijmecsci.2014.08.009.

[199] J. Wieding, R. Souffrant, W. Mittelmeier, R. Bader, Finite element analysis on the biomechanical stability of open porous titanium scaffolds for large segmental bone defects under physiological load conditions, Med. Eng. Phys. 35 (2013) 422-432. doi:10.1016/j.medengphy.2012.06.006.

[200] W. Sun, B. Starly, A. Darling, C. Gomez, Computer-aided tissue engineering: Application to biomimetic modelling and design of tissue scaffolds, Biotechnol. Appl. Biochem. 39 (2004) 49-58. doi:10.1042/BA20030109.

[201] A.L. Olivares, È. Marsal, J.A. Planell, D. Lacroix, Finite element study of scaffold architecture design and culture conditions for tissue engineering, Biomaterials. 30 (2009) 6142-6149. doi:10.1016/j.biomaterials.2009.07.041.

[202] T.B. Sercombe, X. Xu, V.J. Challis, R. Green, S. Yue, Z. Zhang, P.D. Lee, Failure modes in high strength and stiffness to weight scaffolds produced by Selective Laser Melting, Mater. Des. 67 (2015) 501-508. doi:10.1016/J.MATDES.2014.10.063.

[203] I. Yadroitsev, P. Bertrand, I. Smurov, Parametric analysis of the selective laser melting process, Appl. Surf. Sci. 253 (2007) 8064-8069. doi:10.1016/j.apsusc.2007.02.088.

[204] P.D. Lee, P.N. Quested, M. McLean, Modelling of Marangoni effects in electron beam melting, Philos. Trans. R. Soc. London. Ser. A Math. Phys. Eng. Sci. 356 (1998) 1027-1043. doi:10.1098/rsta.1998.0207.

[205] M. Rombouts, J.P. Kruth, L. Froyen, P. Mercelis, Fundamentals of Selective Laser Melting of alloyed steel powders, CIRP Ann. 55 (2006) 187-192. doi:10.1016/S0007-8506(07)60395-3.

[206] A.V. Gusarov, I. Yadroitsev, P. Bertrand, I. Smurov, Heat transfer modelling and stability analysis of selective laser melting, Appl. Surf. Sci. 254 (2007) 975-979. doi:10.1016/j.apsusc.2007.08.074.

[207] T.H.C. Childs, C. Hauser, M. Badrossamay, Mapping and Modelling Single Scan Track Formation in Direct Metal Selective Laser Melting, CIRP Ann. 53 (2004) 191-194. doi:10.1016/S0007-8506(07)60676-3.

[208] J. Ciurana, L. Hernandez, J. Delgado, Energy density analysis on single tracks formed by selective laser melting with CoCrMo powder material, Int. J. Adv. Manuf. Technol. 68 (2013) 1103-1110. doi:10.1007/s00170-013-4902-4.

[209] M.W. Schraad, F.H. Harlow, A stochastic constitutive model for disordered cellular materials: Finite-strain uni-axial compression, 43 (2005) 3542-3568. doi:10.1016/j.ijsolstr.2005.05.018.

[210] T.M. Mower, M.J. Long, Mechanical behavior of additive manufactured, powder-bed laser-fused materials, Mater. Sci. Eng. A. 651 (2016) 198-213. doi:10.1016/j.msea.2015.10.068.

[211] R. Paskaramoorthy, S. Bugarin, R.G. Reid, Analysis of stress concentration around a spheroidal cavity under asymmetric dynamic loading, Int. J. Solids Struct. 48 (2011) 2255-2263. doi:10.1016/J.IJSOLSTR.2011.04.001.

[212] P. Lohmuller, J. Favre, B. Piotrowski, S. Kenzari, P. Laheurte, Stress Concentration and Mechanical Strength of Cubic Lattice Architectures, Materials (Basel). 11 (2018) 1146. doi:10.3390/ma11071146.

[213] Z. Xu, W. Wen, T. Zhai, Effects of Pore Position in Depth on Stress/Strain Concentration and Fatigue Crack Initiation, Metall. Mater. Trans. A. 43 (2012) 2763-2770. doi:10.1007/s11661-011-0947-x.

[214] R. Hedayati, S.M. Ahmadi, K. Lietaert, B. Pouran, Y. Li, H. Weinans, C.D. Rans, A.A. Zadpoor, Isolated and modulated effects of topology and material type on the mechanical properties of additively manufactured porous 
biomaterials, J. Mech. Behav. Biomed. Mater. 79 (2018) 254-263. doi:10.1016/J.JMBBM.2017.12.029.

[215] S. Ghouse, S. Babu, K. Nai, P.A. Hooper, J.R.T. Jeffers, The influence of laser parameters, scanning strategies and material on the fatigue strength of a stochastic porous structure, Addit. Manuf. 22 (2018) 290-301. doi:10.1016/J.ADDMA.2018.05.024.

[216] S. Bose, S.F. Robertson, A. Bandyopadhyay, Surface modification of biomaterials and biomedical devices using additive manufacturing, Acta Biomater. 66 (2018) 6-22. doi:10.1016/J.ACTBIO.2017.11.003.

[217] A. Ataee, Y. Li, M. Brandt, C. Wen, Ultrahigh-strength titanium gyroid scaffolds manufactured by selective laser melting (SLM) for bone implant applications, Acta Mater. 158 (2018) 354-368. doi:10.1016/J.ACTAMAT.2018.08.005.

[218] C.N. Kelly, J. Francovich, S. Julmi, D. Safranski, R.E. Guldberg, H.J. Maier, K. Gall, Fatigue behavior of As-built selective laser melted titanium scaffolds with sheet-based gyroid microarchitecture for bone tissue engineering, Acta Biomater. 94 (2019) 610-626. doi:10.1016/j.actbio.2019.05.046.

[219] G. Nicoletto, Directional and notch effects on the fatigue behavior of as-built DMLS Ti6Al4V, Int. J. Fatigue. 106 (2018) 124-131. doi:10.1016/J.IJFATIGUE.2017.10.004.

[220] J.W. Pegues, N. Shamsaei, M.D. Roach, R.S. Williamson, Fatigue life estimation of additive manufactured parts in the as-built surface condition, Mater. Des. Process. Commun. 1 (2019) e36. doi:10.1002/mdp2.36.

[221] S.-M.-J. Razavi, P. Ferro, F. Berto, Fatigue Assessment of Ti-6Al-4V Circular Notched Specimens Produced by Selective Laser Melting, Metals (Basel). 7 (2017) 291. doi:10.3390/met7080291.

[222] M.R. Loos, L.A.F. Coelho, S.H. Pezzin, S.C. Amico, Effect of carbon nanotubes addition on the mechanical and thermal properties of epoxy matrices, Mater. Res. 11 (2008) 347-352. doi:10.1590/S1516-14392008000300019.

[223] R. Atif, I. Shyha, F. Inam, The degradation of mechanical properties due to stress concentration caused by retained acetone in epoxy nanocomposites, 41 (2016). doi:10.1039/c6ra00739b.

[224] P.Y. Volosevich, A. V. Shiyan, Stress concentration and strain hardening in structural steel, Steel Transl. 45 (2015) 460465. doi:10.3103/S0967091215060145.

[225] A. Fitzner, J. Palmer, B. Gardner, M. Thomas, M. Preuss, J.Q. da Fonseca, On the work hardening of titanium: new insights from nanoindentation, J. Mater. Sci. 54 (2019) 7961-7974. doi:10.1007/s10853-019-03431-w.

[226] H. Bhadeshia, R. Honeycombe, H. Bhadeshia, R. Honeycombe, Strengthening of Iron and Its Alloys, Steels Microstruct. Prop. (2017) 23-57. doi:10.1016/B978-0-08-100270-4.00002-0.

[227] E. Østby, Z.L. Zhang, C. Thaulow, Constraint effect on the near tip stress fields due to difference in plastic work hardening for bi-material interface cracks in small scale yielding, Int. J. Fract. 111 (2001) 87-103. doi:10.1023/A:1010992906312.

[228] R.A. Ainsworth, Stress Redistribution Effects on Creep Crack Growth, in: Mech. Creep Brittle Mater. 1, Springer Netherlands, Dordrecht, 1989: pp. 13-21. doi:10.1007/978-94-009-1117-8_2.

[229] A.A. Griffith, The Phenomena of Rupture and Flow in Solids, Philos. Trans. R. Soc. A Math. Phys. Eng. Sci. 221 (1921) 163-198. doi:10.1098/rsta.1921.0006.

[230] S. Gorsse, C. Hutchinson, M. Gouné, R. Banerjee, Additive manufacturing of metals: a brief review of the characteristic microstructures and properties of steels, Ti-6Al-4V and high-entropy alloys, Sci. Technol. Adv. Mater. 18 (2017) 584-610. doi:10.1080/14686996.2017.1361305.

[231] P. Krakhmalev, G. Fredriksson, I. Yadroitsava, N. Kazantseva, A. du Plessis, I. Yadroitsev, Deformation Behavior and Microstructure of Ti6Al4V Manufactured by SLM, Phys. Procedia. 83 (2016) 778-788. doi:10.1016/J.PHPRO.2016.08.080.

[232] M. Simonelli, Y.Y. Tse, C. Tuck, The formation of $\alpha+\beta$ microstructure in as-fabricated selective laser melting of Ti6Al-4V, J. Mater. Res. 29 (2014) 2028-2035. doi:10.1557/jmr.2014.166.

[233] M. Simonelli, Y.Y. Tse, C. Tuck, Microstructure of Ti-6Al-4V produced by selective laser melting, J. Phys. Conf. Ser. 371 (2012) 012084. doi:10.1088/1742-6596/371/1/012084.

[234] S. Zaefferer, A study of active deformation systems in titanium alloys: dependence on alloy composition and correlation with deformation texture, Mater. Sci. Eng. A. 344 (2003) 20-30. doi:10.1016/S0921-5093(02)00421-5.

[235] L.E. Murr, S.M. Gaytan, F. Medina, H. Lopez, E. Martinez, B.I. MacHado, D.H. Hernandez, L. Martinez, M.I. Lopez, 
R.B. Wicker, J. Bracke, Next-generation biomedical implants using additive manufacturing of complex cellular and functional mesh arrays, Philos. Trans. R. Soc. A Math. Phys. Eng. Sci. 368 (2010) 1999-2032. doi:10.1098/rsta.2010.0010.

[236] G.E. Ryan, A.S. Pandit, D.P. Apatsidis, Porous titanium scaffolds fabricated using a rapid prototyping and powder metallurgy technique, Biomaterials. 29 (2008) 3625-3635. doi:10.1016/j.biomaterials.2008.05.032.

[237] S.J. Hollister, Scaffold engineering: a bridge to where?, Biofabrication. 1 (2009) 012001. doi:10.1088/1758$5082 / 1 / 1 / 012001$.

[238] S. Truscello, G. Kerckhofs, S. Van Bael, G. Pyka, J. Schrooten, H. Van Oosterwyck, Prediction of permeability of regular scaffolds for skeletal tissue engineering: A combined computational and experimental study, Acta Biomater. 8 (2012) 1648-1658. doi:10.1016/j.actbio.2011.12.021. 